\title{
Produced water re-injection in a non-fresh water aquifer with geochemical reaction, hydrodynamic molecular dispersion and adsorption kinetics controlling: model development and numerical simulation
}

\author{
Ibidapo Obe $^{1}$ - T. A. Fashanu ${ }^{1}$ Peter O. Idialu ${ }^{1}$ Tope O. Akintola ${ }^{2}$. \\ Kingsley E. Abhulimen ${ }^{2}$
}

Received: 20 October 2013/Accepted: 11 October 2016/Published online: 27 December 2016

(C) The Author(s) 2016. This article is published with open access at Springerlink.com

\begin{abstract}
An improved produced water reinjection (PWRI) model that incorporates filtration, geochemical reaction, molecular transport, and mass adsorption kinetics was developed to predict cake deposition and injectivity performance in hydrocarbon aquifers in Nigeria oil fields. Thus, the improved PWRI model considered contributions of geochemical reaction, adsorption kinetics, and hydrodynamic molecular dispersion mechanism to alter the injectivity and deposition of suspended solids on aquifer wall resulting in cake formation in pores during PWRI and transport of active constituents in hydrocarbon reservoirs. The injectivity decline and cake deposition for specific case studies of hydrocarbon aquifers in Nigeria oil fields were characterized with respect to its well geometry, lithology, and calibrations data and simulated in COMSOL multiphysics software environment. The PWRI model was validated by comparisons to assessments of previous field studies based on data and results supplied by operator and regulator. The results of simulation showed that PWRI performance was altered because of temporal variations and declinations of permeability, injectivity, and cake precipitation, which were observed to be dependent on active adsorption and geochemical reaction kinetics coupled with filtration scheme and molecular dispersion. From the observed results and findings, transition time $t_{\mathrm{r}}$ to cake nucleation and growth were dependent on aquifer constituents, well capacity, filtration coefficients, particle-to-
\end{abstract}

Kingsley E. Abhulimen

syntechsysworld@gmail.com

1 Department of Systems Engineering, University of Lagos, Lagos, NG, Nigeria

2 Department of Chemical and Petroleum Engineering, University of Lagos, Lagos, NG, Nigeria grain size ratio, water quality, and more importantly, particle-to-grain adsorption kinetics. Thus, the results showed that injectivity decline and permeability damage were direct contributions of geochemical reaction, hydrodynamic molecular diffusion, and adsorption kinetics to the internal filtration mechanism, which are largely dependent on the initial conditions of concentration of active constituents of produced water and aquifer capacity.

Keywords Reinjection - PWRI - Cake formation · Aquifer - Adsorption kinetics - Produced water

$\begin{array}{ll}\text { List of Symbols } \\ S_{\mathrm{T}} & \text { Skin factor } \\ \mu & \text { Viscosity } \\ P_{\text {inj }} & \text { Injection pressure } \\ q & \text { Flow rate }\left(\mathrm{m}^{3} / \mathrm{s}\right) \\ k & \text { Permeability } \\ k_{\sigma} & \text { Permeability damage factor } \\ \eta & \text { Total collision probability } \\ \eta_{1} & \text { Collision probability due to interception } \\ \eta_{\mathrm{D}} & \text { Collision probability due to diffusion } \\ \eta_{\mathrm{lm}} & \text { Collision probability due to impaction } \\ \eta_{\mathrm{s}} & \text { Collision probability due to sedimentation } \\ \eta_{\mathrm{E}} & \text { Collision probability due to surface forces } \\ \mathrm{d}_{\mathrm{p}} & \text { Particle diameter } \\ \mathrm{d}_{\mathrm{g}} & \text { Grain diameter } \\ \phi & \text { Effective porosity } \\ \rho_{\mathrm{p}} & \text { Particle density } \\ \rho_{\mathrm{f}} & \text { Fluid density } \\ U, u & \text { Darcy's velocity } \\ \mathrm{g} & \text { Gravity acceleration }\left(\mathrm{m} / \mathrm{s}^{2}\right) \\ T & \text { Absolute temperature } \mathrm{K}\left({ }^{\circ} \mathrm{C}\right) \\ C(r, t) & \text { Volumetric concentrations of suspended particles, } \\ & \text { ppm }\end{array}$


$\sigma(r, t)$ Volumetric concentrations of the deposited particles, ppm

ko Absolute permeability

$\lambda \quad$ Filtration coefficient

$L \quad$ Depth of the porous media

$\varepsilon_{\mathrm{r}} \quad$ Scaled length in radial direction

$\varepsilon_{\mathrm{z}} \quad$ Scaled length in axial direction

$t \quad$ Time (years)

$\tau \quad$ Scaled time

$\in \quad$ Scaled concentration of suspended solids

$S \quad$ Scaled concentration of deposited particles

$\lambda_{\mathrm{o}} \quad$ Initial filtration coefficient

$\alpha_{c} \quad$ Clean bed collision efficiency

I Injectivity index

$J \quad$ Inverse of injectivity index

$T_{\mathrm{r}} \quad$ Transition time

$N \quad$ Number of particles attached to one grain

$J_{\mathrm{d}} \quad$ Impedance during one-phase suspension flow

$K_{\text {ror }} \quad$ Relative permeability of residual oil

$m \quad$ Slope of impedance straight line during deep bed filtration for one-phase suspension flow

$m_{\mathrm{c}} \quad$ Slope of impedance straight line during external cake formation for one-phase suspension flow

$p \quad$ Pressure $\left(\mathrm{M} / \mathrm{LT}_{2} \mathrm{~Pa}\right)$

$q \quad$ Total flow rate per unit reservoir thickness $\left(\mathrm{L}^{2} / \mathrm{T}\right)$

$r \quad$ Reservoir radius $(\mathrm{L}, \mathrm{m})$

$r_{\mathrm{w}} \quad$ Well radius $(\mathrm{L} / \mathrm{m})$

$r_{\mathrm{d}} \quad$ Damage zone radius $(\mathrm{L}, \mathrm{m})$

$R_{\mathrm{c}} \quad$ Contour radius $(\mathrm{L} / \mathrm{m})$

$S_{\text {or }} \quad$ Residual oil saturation

$S_{\text {wi }} \quad$ Initial water saturation

$T \quad$ Time (T, s)

$T \quad$ Dimensionless time

$T_{\mathrm{tr}} \quad$ Dimensionless transition time

$U$ Total flow velocity ( $\mathrm{L} / \mathrm{T}, \mathrm{m} / \mathrm{s})$

$\alpha \quad$ Critical porosity fraction

$\beta \quad$ Formation damage coefficient

$\varphi \quad$ Porosity

\section{Definition of terms and acronyms}

Produced water

Produced water re-injection

Non-fresh water hydrocarbon aquifer Reservoir

Formation
Water associated with crude oil exploration and production

Sending back produced water from the surface into the subsurface

Crude oil bearing formation

A permeable subsurface rock that contains petroleum

Refers to the reservoir bearing fluids, e.g., oil, gas, and water
Produced water

constituents

Injection pipe

Well bore

Deep bed filtration

Injectivity decline

Formation

damage

Adsorption

kinetics

Hydrodynamic

dispersion

Geochemical

reaction

Colloids

Scales

Cakes

Geomechanics

Corrosion

Souring

Representative

Elementary volume

Isotherms

Finite-element

method

PW

PWRI

EOR
Heavy metals, suspended solids, dissolved solids, hydrocarbon traces, etc.

Produced water transfer medium from surface to sub-surface

Point of contact of injection pipe with formation/reservoir

The flow and deposition of particles in the rock matrix

Index signifying the change in the injection rate of the injected fluid

Reduction in aquifer properties that are solely responsible for the transmissibility of reservoir fluids through the pore spaces (fracture in internal walls of the aquifer)

Attraction and retention of particle to the surface grain and the preference of this particle for a particular site within the reservoir

Is a term used to include both diffusion and dispersion of particles within a medium

This is the interaction of species constituents in the produced water and the formation of the host aquifer

Colloidal particles are suspended particles carried in the fluid stream Result of nucleation of colloids

Deposition of scales in pore sites is referred to as cakes

Involves the geologic study of the behaviour of soil and rock

Loss in metal due to degradation, erosion or prevailing ambient conditions

Acidic smell/taste characteristic

A pictured or drawn shape representative of the actual shape. Used in solving mathematical problems

Equations considered at constant temperature

Numerical method of solution whereby a problem is characterized by boundaries and solved within these boundaries

Produced water

Produced water re-injection

Enhanced oil recovery 

E \& $P$
Exploration and production
REV
Representative elementary volume
TVD
Total vertical depth
BHP
Bottom hole pressure

\section{Introduction}

Reinjection of produced water into spent hydrocarbon aquifer also referred to as produced water reinjection (PWRI) is one of the earliest and most environment friendly methods to dispose produced water from production platforms. However, reinjection of produced water degrades the aquifer that results in injectivity decline, fracturing of the internal walls of the aquifer and later formation damage, as shown in Fig. 1. Thus, PWRI has reduced performance over a period, because the method cannot be sustained throughout the production life of the reservoir.

Previous studies and models described processes and mechanisms that resulted in formation damage and cake formation which were well developed and documented in technical literatures. PWRI in aquifers is generally studied under two research domains: (1) internal filtration and (2) external cake build up (Bedrikovetsky et al. 2001; Bedrikovetsky et al. 2007; Wennberg and Sharma 1997; Farajzadeh 2002; AlAbduwani 2005). Significant research works and models were advanced and documented in several technical literatures to predict injectivity and characterize formation damage system and well behavior (Pang and Sharma 1994, 1997; Ojukwu and van den Hoek 2004; Guedes et al. 2006; Yerramilli et al. 2013).

Precious studies show that formation damage and injectivity decline are two major drawbacks associated with PWRI performance in hydrocarbon aquifer. Some past and recent studies were focused on understanding formation damage mechanisms (Salehi and Settari 2008; Prasad et al. 1999; Davidson 1979; Marchesin et al. 2011; Abou-Sayed et al. 2005; Zhang et al. 1993; Todd 1979; Ochi et al. 2007; Nabzar et al. 1997; De Zwart 2007; Faruk 2010; Lawal et al. 2011; Lawal and Vesovic 2010; Wang and Le 2008; Li et al. 2012).

There are other studies and models available in technical literature targeted to predict injectivity decline from par- ticulate mechanics and flow transport. Notable contributions in this regard include work of Barkman and Davidson (1972), Pang and Sharma $(1994,1997)$ as well as Wennberg and Sharma (1997). In theory, efficiency and sustainability of the PWRI were progressed by considering injectivity decline as an outcome of momentum and particulate transport phenomena in porous media (Mendez 1999). There are other model and studies reported in technical literatures by previous researchers that focused on the filtration coefficient as the sole determinant of injectivity decline and fracturing (Abou-Sayed et al. 2007; Ajay and Sharman 2007, Al-Abduwani et al. 2001; Altoef et al. 2004; Chang 1985; Clifford et al. 1991; Donaldson et al. 1977; Doresa et al. 2012; Folarin et al. 2013; Gong et al. 2013; Hustedt et al. 2006). None of these models hinted on possible geochemical reaction of produced water heavy metals and aquifer water constituents and effect of geochemical reaction, the focus of this research study.

Nevertheless, recent findings (Idialu 2014) suggest a significant role of adsorption, geochemical reaction and molecular transport kinetics in well behavior, cake formation and damage characterization in PWRI modeling, and field data analysis. Therefore, this paper considers the effects of geochemical reaction, adsorption kinetics, and hydrodynamic molecular transport in formation damage and injectivity decline modeling and developments. Performance of PWRI water injectivity decline as a function of injection water quality, rates, and pressures was found to be significant factors in well injection design and formulation of secondary and tertiary recovery strategies. The effect of geochemical reaction in scale formation to injectivity decline was considered in the PWRI model analysis while outlining also the role of adsorption kinetics and molecular transport. The justification of this work inspired by the significant and active research interest over the last decade in the use of produced water as a resource in reinjection as alternative secondary and tertiary recovery method could achieve the goals of the zero tolerance by regulatory authority to water disposal management to maintain marine life and environment sustainability.
Fig. 1 Collapsed features where fracture will be more prevalent

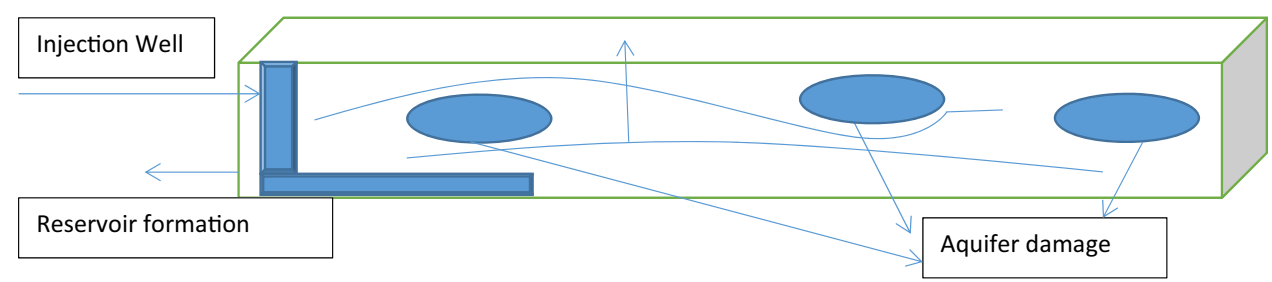




\section{Model development}

The aquifer grid for produced water system and geometry of the PWRI schemes in well-reservoir formation, effects, and problems encountered were illustrated in Figs. 2 and 3, respectively. The implications arising from PWRI management are: (1) injectivity loss; (2) permeability loss; (3) loss of recovery; (4) loss in reservoir potential; (5) poor reservoir sweep (bypass oil and early water breakthrough); (6) excessive chemical treatment; and (7) discharge not meeting environmental regulations.

The generalized improved PWRI model incorporated molecular transport, geochemical, and adsorption kinetics in Eq. 1 with boundary conditions presented in Eqs. 2, 3, and 4:
Fig. 2 Generic aquifer grid system for produced water re-injection system. Cin Concentration of active constituents in produced water in Reservoir-Aquifer Control volume grid, Cout

Concentration of active constituents in produced water out Reservoir-Aquifer Control volume grid. $U_{x}$ in, $U_{y}$ in, $U_{z}$ in is the velocity of produced water in Cartesian coordinates $x, y, z$ in Reservoir-Aquifer Control volume grid. $U_{x o u t}$, $U_{\text {yout }}, \mathrm{U}_{\text {zout }}$ is the velocity of produced water in Cartesian coordinates $x, y, z$ out Reservoir-Aquifer Control volume grid

Fig. 3 Geometry of PWRI in well-reservoir formation
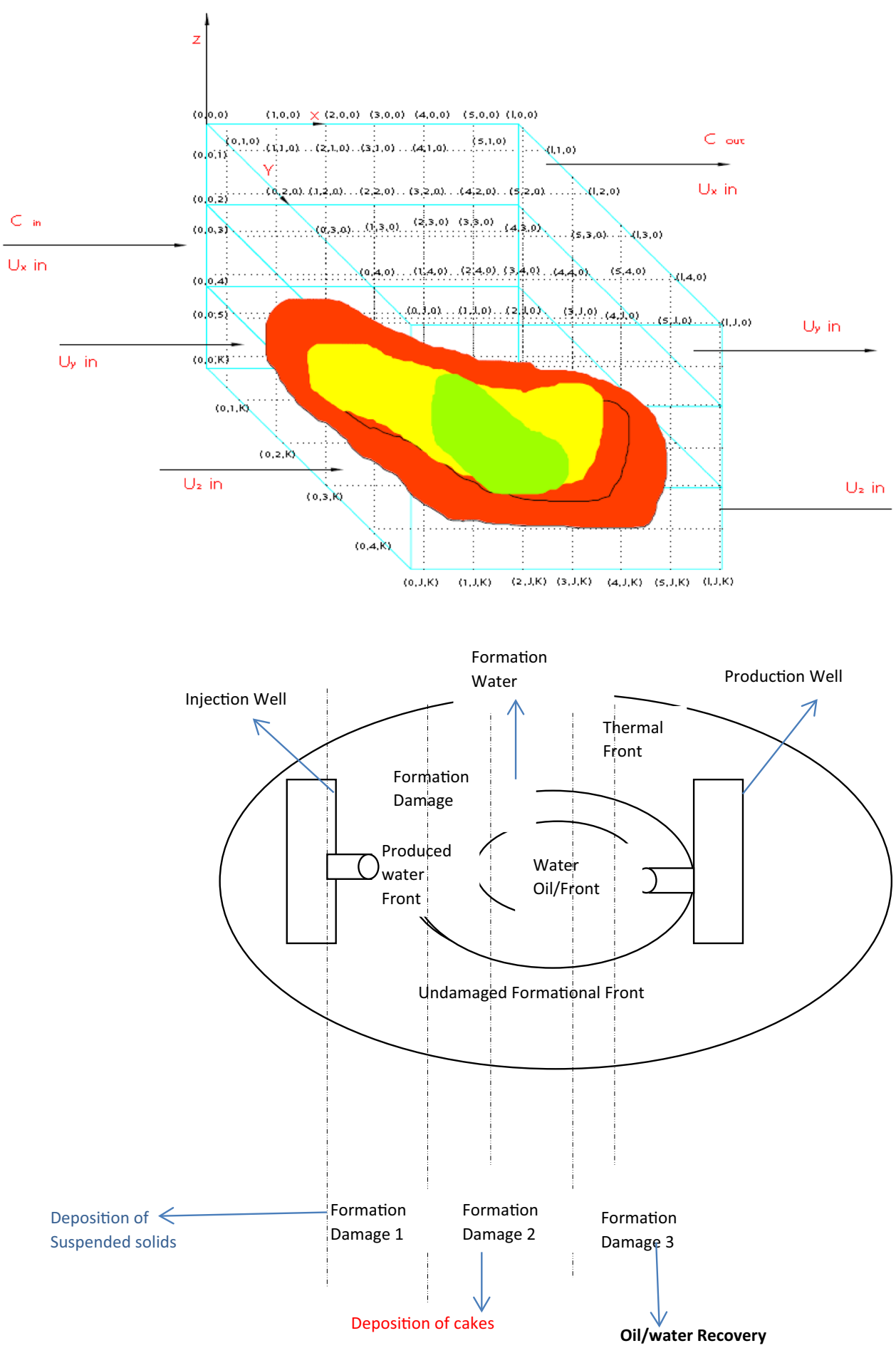


$$
\begin{gathered}
\frac{\partial \phi(t) C}{\partial t}+\nabla(C v)-\nabla^{2}(D C)=-\left(\sigma_{\mathrm{n}}+R_{\mathrm{d}}\right)+R_{\mathrm{n}} \\
C=C(x, z, t) ; 0 \leq x \leq L ; 0 \leq z \leq Z ; t \geq 0 \\
C(x, z, 0)=C_{0}
\end{gathered}
$$

where $C$ is the concentration of produced water active constituents, $C_{0}$ is the initial concentration of the active constituents, $v$ is the produced water transport velocity in the geologic formation, $\phi(t)$ is the variable porosity, $D$ is the molecular diffusivity, and $t$ is time.

The significant control variables in improved PWRI model are as follows:

$\sigma_{\mathrm{n}}$ deposition filtration term, $R_{\mathrm{n}}$ geochemical reaction term, $R_{\mathrm{d}}$ adsorption kinetics term, $D C$ molecular transport term.

In this work, the geochemical reaction rate mechanism was described to follow second-order kinetics summarized as Eqs. 5 and 7 as follows.

At time $t=0$

$\begin{array}{lll}C_{\mathrm{Ao}} & C_{\mathrm{Bo}} \longrightarrow X & C_{\mathrm{co}} \\ C_{\mathrm{Ao}}-X_{\mathrm{r}} C_{\mathrm{Ao}} & C_{\mathrm{Bo}}-X_{r} C_{\mathrm{Bo}} & C_{\mathrm{co}}+X_{\mathrm{r}} C_{\mathrm{Co}} .\end{array}$

At time $t=t$

$\begin{array}{lll}C_{\mathrm{A}} & C_{\mathrm{B}} & C_{\mathrm{C}} .\end{array}$

$1 \mathrm{~mol}$ of Component A reacted with $1 \mathrm{~mol}$ of Component $\mathrm{B}$ to produce $1 \mathrm{~mol}$ of scale products:

$R_{\mathrm{n}}=\frac{1}{V_{\mathrm{fm}}} \frac{\partial C}{\partial t}=K_{\mathrm{o}}\left(\frac{C_{\mathrm{T}}}{1+\sum K_{i} C_{i}}\right)\left(C_{\mathrm{A}} C_{\mathrm{B}}-K_{1} C\right)$

$R_{\mathrm{n}}=\frac{\partial R_{\mathrm{rn}}}{\partial t}=K_{o}\left(\frac{C_{\mathrm{T}}}{1+\sum K_{i} C_{i}}\right)\left(C_{\mathrm{A}} C_{\mathrm{B}}-K_{1} C\right)$.

These important contributions in the improved model were used to standardize the general performance of produced water reinjection in hydrocarbon aquifers, with geochemical reaction, adsorption kinetics, and hydrodynamic dispersion transport that highlighted as the key performance indicators of the improved model, as illustrated in subsequent sections (see Fig. 4).

Invasion Zone Front 1

To account for adsorption kinetics ( $\mathrm{Rd}$ ) in internal filtration modeling, three linear adsorption isotherms which are Linear; Langmuir, and Freundlich isotherms were considered. Single particle (suspended) linear adsorption is shown in

$C_{\mathrm{s}}=K_{\mathrm{a}} C$.

To determine the active mass transfer coefficient $\left(K_{\mathrm{a}}\right)$, the Arrhenius equation is introduced as follows:

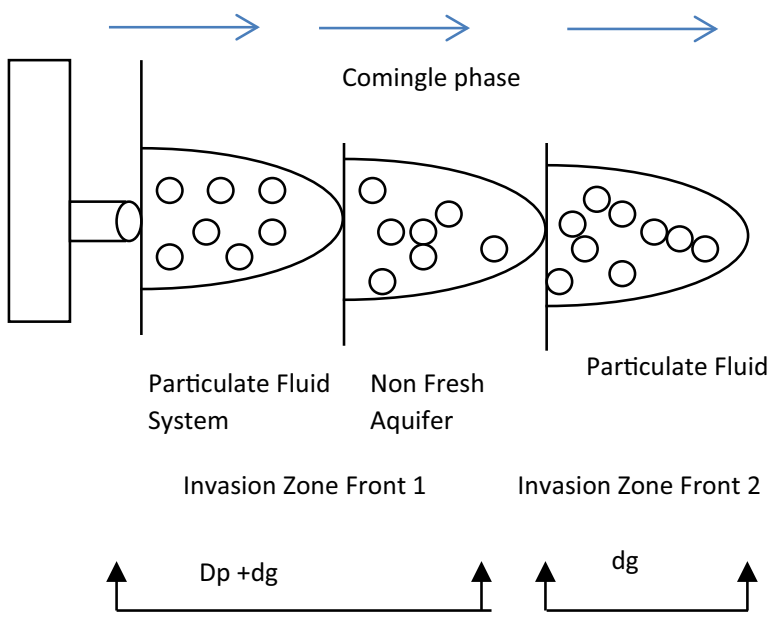

Fig. 4 Micro pore particle retention kinetics

$K_{\mathrm{a}}=K_{\mathrm{o}} e^{-\frac{\Delta H}{R T}}$.

The $R_{\mathrm{d}}$ macroscale adsorption particle retention kinetics (adsorption) on the surface of grain were computed and presented as Eq. 9:

$$
\begin{aligned}
\frac{\partial C_{i}}{\partial t} & +\left(v_{z} \frac{\partial C_{i}}{\partial z}+\frac{v_{\theta}}{r} \frac{\partial C_{i}}{\partial \theta}+\frac{v_{r}}{r} \frac{\partial r C_{i}}{\partial r}\right) \\
& -\left(D_{z} \frac{\partial^{2} C_{i}}{\partial z^{2}}+D_{r}\left(\frac{\partial^{2} C_{i}}{\partial r^{2}}+\frac{1}{r} \frac{\partial C_{i}}{\partial r}\right)\right) \\
& =R_{\mathrm{d}} .
\end{aligned}
$$

With $R_{\mathrm{d}}$ is given by Eq. 12 :

$R_{d}=E_{\mathrm{mp}}\left(\frac{1-\varphi_{\mathrm{mp}}}{\varphi_{\mathrm{mp}}}\right)\left(\frac{3 K_{g}}{R}\right)\left(C_{i}-\frac{C_{T} K_{i} C_{i}}{1+\sum_{1=n}^{n} K_{i} C_{i}}\right)$

where $E_{\mathrm{mp}}$ is defined as trapping efficiency factor. For particulate transport systems at the PW invasion zone when $t=0$ and $0<t<t_{i}$, where $t_{i}$ is the residence time of the particle in invasion zone Li. Previous studies illustrated that the suspended particles adsorbed have different dynamics in each invasion zone in the aquifer, thus the transport equation becomes

$$
\begin{aligned}
& \left(\frac{\partial C_{i}}{\partial t}\right)_{L_{i}}+\left(E_{\mathrm{mp}}\left(\frac{1-\varphi_{\mathrm{mp}}}{\varphi_{\mathrm{mp}}}\right)\right)_{L_{i}}\left(\frac{\hat{k} k_{g}}{R}\left(C_{\mathrm{T}}-\frac{C_{\mathrm{T}} k_{i} c_{i}}{1+\sum k_{i} c_{i}}\right)\right)_{L_{i}} \\
& =\left(-V_{\mathrm{Z}} \frac{\partial c_{i}}{\partial z}\right)_{L_{i}}+\left(-\frac{V_{\theta} \partial c_{i}}{r}\right)_{L_{i}}+\left(-\frac{V_{r}}{r}\left(\frac{\partial}{\partial r}\left(r c_{i}\right)\right)\right)_{L_{i}} \\
& +\left(D_{z} \frac{\partial^{2} c_{i}}{\partial z^{2}}\right)_{L_{i}}+\left(D_{r}\left(\frac{\partial^{2} c_{i}}{\partial r^{2}}+\frac{1 \partial c_{i}}{r} \frac{\partial}{\partial r}\right)\right)_{L_{i}} \\
& 0<L_{i}<L_{T_{i}} .
\end{aligned}
$$

The improved PWRI model in generalized dimensionless form accounts for residual oil mobility $S_{\text {or }}$ and permeability $k_{\text {or }}$, porous media particle retention adsorption factor in Eq. 12: 


$$
\begin{aligned}
& \left(\frac{\partial \zeta}{\partial \tau^{*}}-\left(\frac{\partial S}{\partial \tau^{*}}+\left(\frac{q_{\mathrm{o}}}{c_{\mathrm{o}}}\right) \frac{\partial \Psi_{\mathrm{D}}}{\partial \tau^{*}}\right)+\left(\frac{R_{\mathrm{o}}}{c_{\mathrm{o}}}\right) \frac{\partial \Psi_{\mathrm{r}}}{\partial \tau^{*}}\right) \\
& +\alpha_{1}(v)\left(\frac{\partial \zeta}{\partial \varepsilon_{\mathrm{r}}}\right)+\alpha_{2}(v) \frac{\zeta}{\varepsilon_{\mathrm{r}}}+\alpha_{3}(v) \frac{\partial \zeta}{\partial \varepsilon_{\mathrm{z}}} \\
& \quad=\alpha_{4}(v) \frac{\partial^{2} \zeta}{\partial r^{2}}+\alpha_{5}(v)\left(\frac{\partial \zeta}{\partial \varepsilon_{\mathrm{r}}}\right)+\alpha_{6}(v)\left(\frac{\partial^{2} \zeta}{\partial \varepsilon_{\overline{\mathrm{z}}}^{2}}\right) .
\end{aligned}
$$

Iwaski (1937) proposed the filtration model in Eq. 15 which represented the rate of particle trapping:

$\frac{\partial \sigma}{\partial t}=\lambda v C$

where $v$ is the superficial velocity, $\lambda$ is defined as the filtration coefficient, a function of a large number of parameters, and $C$ is the fraction of suspended particles per unit volume of suspension.

The rate of deposition was proportional to the concentration of suspended particles and fluid velocity, see Eq. 14:

$\frac{\partial \sigma}{\partial t}=\lambda\|U\| C_{s}$

The filtration coefficient was computed by the relation Eq. 17:

$\lambda=\frac{3}{2}\left(\frac{1-\phi}{d_{s}}\right) \alpha_{c} n$

where $\propto_{c}$ represents the total collision probability of the bed efficiency and $\mathrm{n}$ is the collision probability of the filtration mechanisms.

The Filtration Coefficient Numerical Model was computed as Eq. 16:

$\left[\begin{array}{r}S_{i 1} \\ S_{i 2} \\ S_{i 3} \\ \vdots \\ \vdots \\ S_{i n}\end{array}\right]_{K+1}=\left[\begin{array}{r}S_{i 1} \\ S_{i 2} \\ S_{i 3} \\ \vdots \\ \vdots \\ S_{i n}\end{array}\right]_{K}+\alpha_{0}\left[\begin{array}{r}\epsilon_{i 1} \\ \epsilon_{i 2} \\ \epsilon_{i 3} \\ \vdots \\ \vdots \\ \epsilon_{i n}\end{array}\right]_{K}$

We assumed the following in the development of improved PWRI model:

(a) The displacing fluid (water) and the deposited solids were considered incompressible.

(b) The densities of the solid particles were considered equal in both dispersed and deposited states.

(c) The linear velocity in $v_{r}, v_{z}$, and $v_{\varphi}$ along the core is constant. In addition, we assumed a constant velocity with time. Therefore, the conservation of the total flux is $\mathrm{d} \omega v=0$.

(d) The kinetics of the particles was considered linear. (e) Dependency of the viscosity and concentration was considered negligible.

(f) Thermal and shear stresses were considered negligible.

The injectivity index was computed as flow rate per unit of the pressure drop between the injector and the reservoir and computed, see formula as shown in

$\prod=\frac{q(t)}{\Delta p(t)}$.

The impedance was computed as the inverse of the dimensionless injectivity index:

$J(T)=\frac{\prod(0)}{\prod(t)}=\frac{q_{o} \Delta p(T)}{\Delta p(0) q(T)}$.

The impedance was computed as piecewise linear function of the dimensionless time for either deep bed filtration or external cake formation (Pang and Sharma 1994, 1997; Prasad et al. 1999):

$J_{\mathrm{d}}(T)=1+m T \quad$ For $\quad T<T_{\mathrm{r}}$

$J_{\mathrm{d}}(T)=1+m T_{\mathrm{r}}+m_{\mathrm{c}}\left(T-T_{\mathrm{r}}\right)$ For $T>T_{\mathrm{r}}$.

The nucleation or transition time $T_{r}$ was represented as Eq. 22:

$T_{\mathrm{r}}>\frac{2 \alpha r_{\mathrm{w}}}{\lambda C_{\mathrm{o}} R_{\mathrm{C}}^{2}}$.

The impedance slope $\mathrm{m}$ during the deep filtration was computed by the formula of Eq. 22:

$$
\begin{aligned}
m_{\mathrm{c}}= & \frac{k k_{\mathrm{rowr}} \varphi c_{o}}{k_{\mathrm{c}}\left(1-\varphi_{\mathrm{c}}\right) X_{\mathrm{w}}\left(-\operatorname{In} X_{\mathrm{w}}\right)} \\
m= & \left(\frac{\beta \varphi c_{\mathrm{o}}}{\operatorname{In} X_{\mathrm{w}}}\right)\left(\lambda R_{\mathrm{c}}\right)\left(\frac{1}{\sqrt{X_{\mathrm{w}}}}\right)\left(-\exp \left(-\lambda\left(R_{\mathrm{C}}-r_{\mathrm{w}}\right)\right)\right. \\
& -\lambda R_{C} \exp \left(\lambda r_{\mathrm{w}}\right) \int_{\lambda r_{\mathrm{w}}}^{\lambda R_{\mathrm{c}}} \frac{\exp (-u)}{u} \mathrm{~d} u
\end{aligned}
$$

where

$u=\lambda R_{\mathrm{c}} \sqrt{X}$

$X=\ell^{2}=\left(\frac{r}{R_{\mathrm{c}}}\right)^{2}$

$X_{\mathrm{w}}=\ell^{2}=\left(\frac{r_{\mathrm{w}}}{R_{\mathrm{c}}}\right)^{2}$.

$m_{\mathrm{c}}$ represent the slope of the external cake formation.

The damage section of the aquifer formation was computed as a ratio of differential in injection pressure over injection rate presented in Eq. 28:

$\frac{\Delta P_{\in}}{q}=\frac{\mu \operatorname{In}\left(\frac{r_{\mathrm{e}}}{r_{\mathrm{w}}}\right)}{2 \pi K_{\mathrm{or}} K_{\sigma}}$. 
The undamaged section was computed as Eq. 29:

$$
\frac{\Delta P}{q}=\frac{\mu \operatorname{In}\left(\frac{r_{\mathrm{e}}}{r_{\mathrm{w}}}\right)}{2 \pi K_{\mathrm{or}}}
$$

Total Injectivity Pressure Gradient $=\frac{\Delta P}{q}+\frac{\Delta P_{\epsilon}}{q}$

$$
=\left(1+K_{\sigma}\right) \frac{\mu \operatorname{In}\left(\frac{r_{\mathrm{e}}}{r_{\mathrm{w}}}\right)}{2 \Pi h K_{\mathrm{or}}}
$$

where

$$
\frac{\Delta P_{\infty}}{q}=\frac{\mu \operatorname{In}\left(\frac{r_{\mathrm{c}}}{r_{\mathrm{ec}}}\right)}{2 \pi K_{\mathrm{or}}}
$$

Total Impedance $=$ Damage Impedance

$$
+ \text { Undamaged Impedance. }
$$

Figure 5 shows the damage section which represents area that has been affected by cake deposits, whereas undamaged section is unaffected by solids deposition.

The total impedance was computed by

$\frac{\Delta P}{q}=\frac{\mu}{2 \pi K_{\mathrm{or}}}\left(\operatorname{In}\left(\frac{r_{\mathrm{e}}}{r_{\mathrm{w}}}\right)+K_{\sigma}^{\prime}\right)$.

The dimensionless form of total impedance index was computed as Eq. 33 as follows:

$$
\frac{\left(\frac{\Delta P}{q}\right)_{T}}{\left(\frac{\Delta P_{\mathrm{O}}}{q_{\mathrm{O}}}\right)}=\frac{\left(\left(\operatorname{In}\left(\frac{r_{\mathrm{e}}}{r_{\mathrm{w}}}\right)+K_{\sigma}^{\prime}\right)\right)_{\mathrm{T}}}{\left(\left(\operatorname{In}\left(\frac{r_{\mathrm{e}}}{r_{\mathrm{w}}}\right)_{\sigma}\right)\right)_{\mathrm{T}}}
$$

where

$j=1+K_{\sigma}^{\prime}\left(\frac{1}{\operatorname{In}\left(\frac{r_{\mathrm{e}}}{r_{\mathrm{w}}}\right)}\right)$.

The injectivity index was computed as the flow rate per unit of the pressure drop between the injector and the reservoir (Eq. 35):

$\prod=\frac{q(t)}{\Delta p(t)}$.

Based on preliminary field data obtained from a field operator and regulator in Nigeria, the model was solved using finite-element method and the injectivity and solid deposition simulated in COMSOL environment. Details of

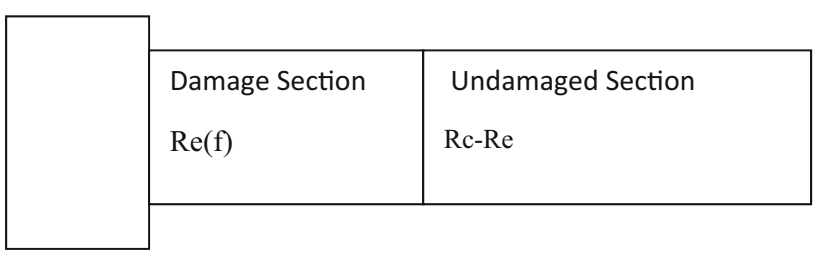

Fig. 5 Damage and undamaged section of a reservoir the finite-element method and COMSOL software algorithms applied to solve the mode were presented in subsequent sections.

\section{Field data, numerical development, and computer simulation}

The improved PWRI model was solved by finite-element method and injectivity and permeability damage simulated in the COMSOL Multiphysics software environment using the field data obtained from regulator for the Onshore Field in Nigeria. In the numerical model, a six-order six-point implicit differencing scheme was used and resulting numerical solution of the governing equations of the PWRI concentration field was solved by the Triadiagonal Matrix Algorithm (TDMA) method. The implicit finite scheme was then applied to the PWRI Model of Eq. 5 to give Eq. 36:

$$
\begin{aligned}
& \alpha_{1}^{\prime} \zeta_{i j k+1}+\alpha_{2}^{\prime} \zeta_{i+1 j k+1}+\alpha_{3}^{\prime} \zeta_{i j+1 k+1}+\alpha_{4}^{\prime} \zeta_{i-1 j k+1}+\alpha_{5}^{\prime} \zeta_{i j-1, k+1} \\
& \quad=\alpha_{6}^{\prime} \zeta_{i j k}+\hat{a}_{r} \Delta q_{r i j k}-\hat{a}_{d} \Delta q_{d i j k}
\end{aligned}
$$

where

the adsorption term in Eq. (37) was specified by Eq. (38):

$$
\begin{aligned}
\Delta q_{d i j k}= & \left(\frac{a_{1}}{\hat{a}_{\mathrm{d}}}\right) \zeta_{i j k+1}-\left(1-\frac{\hat{a}_{2}}{\hat{a}_{\mathrm{d}}}\right) \zeta_{i j k} \\
& +\left(1-\frac{\hat{a}_{2}}{\hat{a}_{\mathrm{d}}}\right)\left(C_{\mathrm{T}} \frac{k_{1}}{1+k_{1} c_{\mathrm{o}} \zeta_{i j k}}\right) \zeta_{i j k} .
\end{aligned}
$$

The other terms in Eq. (36) was defined in line with the reservoir:

$\alpha_{1}^{\prime}=1-\Delta \tau^{*}\left(\frac{\alpha_{1}}{\Delta \epsilon_{\bar{r}}}+\frac{\alpha_{3}}{\Delta \epsilon_{\bar{z}}}-\frac{2 \alpha_{4}}{\left(\Delta \epsilon_{\bar{r}}\right)^{2}}-\frac{2 \alpha_{6}}{\left(\Delta \epsilon_{\bar{z}}\right)^{2}}\right)$

$\alpha_{2}^{\prime}=\left(\frac{\alpha_{1} \Delta \tau^{*}}{\Delta \epsilon_{\bar{r}}}-\frac{\alpha_{4} \Delta \tau^{*}}{\left(\Delta \epsilon_{r}\right)^{2}}+\frac{\alpha_{5} \Delta \tau^{*}}{\Delta \epsilon_{r}}\right)$

$\alpha_{3}^{\prime}=\left(\frac{\alpha_{3} \Delta \tau^{*}}{\Delta \epsilon_{z}}-\frac{\alpha_{6} \Delta \tau^{*}}{\left(\Delta \epsilon_{z}\right)^{2}}\right)$

$\alpha_{4}^{\prime}=\left(\frac{\alpha_{4} \Delta \tau^{*}}{\left(\Delta \epsilon_{r}\right)^{2}}\right)$

$\alpha_{5}^{\prime}=\left(\frac{\alpha_{6} \Delta \tau^{*}}{\left(\Delta \epsilon_{z}\right)^{2}}\right)$

$\alpha_{6}^{\prime}=1-\Delta \tau^{*}\left(\alpha_{\mathrm{o}}+\alpha_{2}\right)$

where

$\alpha_{1}(v)=\left(\frac{v_{\mathrm{r}}}{v}\right)\left(\frac{L}{R_{\mathrm{o}}}\right)$ 
Table 1 Re-injection parameters *source: Energy Tech Co, Houston, Texas, USA and petroleum regulator, Department of Petroleum Resources (DPR), as reported by (Idialu 2014)

\begin{tabular}{|c|c|c|c|c|c|}
\hline Well & Perforations (md) & Tubing size & Inj. press. & Inj. rate & Inj start UP \\
\hline A-5 & $12,173^{\prime}-12,282^{\prime}$ & $4.5^{\prime \prime}$ & 2505 psig & 22 MBWPD & $11 / 19 / 2000$ \\
\hline A-10 & $15,060^{\prime}-15,132^{\prime}$ & $5.5^{\prime \prime}$ & 3342 psig & $20 \mathrm{MBWPD}$ & $5 / 22 / 2001$ \\
\hline A-12 & $17,152^{\prime}-17,258^{\prime}$ & $5.5^{\prime \prime}$ & 2504 psig & $26 \mathrm{MBWPD}$ & $4 / 19 / 2001$ \\
\hline A-14 & $26,772^{\prime}-26,846^{\prime}$ & $5.5^{\prime \prime}$ & 2359 psig & 22 MBWPD & $5 / 16 / 2003$ \\
\hline A-19 & $20,990^{\prime}-21,062^{\prime}$ & $5.5^{\prime \prime}$ & 3240 psig & 19 MBWPD & $12 / 10 / 2001$ \\
\hline
\end{tabular}

$\alpha_{2}(v)=\left(\frac{v_{r}}{v}\right)\left(\frac{L}{R_{o}}\right)\left(\frac{1}{\varepsilon_{r}}\right)$

$\alpha_{3}(v)=\frac{v_{\mathrm{z}}}{v}$

$\alpha_{4}(v)=\left(\frac{D_{\mathrm{er}}}{v}\right)\left(\frac{L}{R_{o}^{2}}\right)$

$\alpha_{5}(v)=\left(\frac{D_{\mathrm{er}}}{v}\right)\left(\frac{L}{R_{0}^{2}}\right)\left(\frac{1}{\varepsilon_{\mathrm{r}}}\right)$

$\alpha_{6}(v)=\left(\frac{D_{e z}}{v}\right)\left(\frac{1}{L}\right)$.

Computation of Velocity in $r$ and $z$ direction:

$$
\begin{aligned}
& v_{r}=\frac{q_{r}}{2 \pi r h}=\left(\frac{K_{\mathrm{or}} K_{\sigma_{r}}}{\mu}\right) \int_{r_{w}}^{r_{e 1}} \frac{1}{r} \frac{\mathrm{d} r P}{\mathrm{~d} r}+\int_{r_{e 1}}^{r_{e}} K_{o r} \frac{1}{r} \frac{\mathrm{d} r P}{\mathrm{~d} r} \\
& v_{z}=\frac{q_{z}}{\pi r^{2} h}=\left(\frac{K_{o z} K_{\sigma_{z}}}{\mu}\right) \int_{r_{w}}^{r_{e 1}} \frac{\mathrm{d} P}{\mathrm{~d} z}+\int_{r_{e 1}}^{r_{e}} K_{o z} \frac{\mathrm{d} P}{\mathrm{~d} z} \\
& \int_{r_{\mathrm{w}}}^{r_{\mathrm{e}}}\left(\frac{q}{2 \pi h}\right) \frac{\mathrm{d} r}{r}=\left(\frac{K_{\mathrm{or}}\left(1+K_{\sigma}\right)}{\mu}\right) \Delta P \\
& \frac{\Delta P}{q}=\frac{\mu \mathrm{In}\left(\frac{r_{\mathrm{e}}}{r_{\mathrm{w}}}\right)}{2 \pi K_{\mathrm{or}}}+\frac{\mu \mathrm{In}\left(\frac{r_{\mathrm{e}}}{r_{\mathrm{w}}}\right)}{2 \pi K_{\mathrm{or}} K_{\sigma}} \\
& \frac{\Delta P}{q}=\frac{1}{2 \pi K_{o r}}\left(1+\frac{1}{K_{\sigma}}\right) .
\end{aligned}
$$

The flow chart in Fig. 4 described the simulation algorithm using the COMSOL Multiphysics software.

\section{Field water compatibility studies for fields in Gulf of Guinea, Nigeria field in Niger Delta}

The data of PWRI case studies for Gulf of Guinea (Niger Delta, Nigeria) were provided in operator's report planned for water flood for secondary enhanced recovery in the Niger Delta region of Nigeria. Five PWRI runs were assessed for this study. The limiting factors for injection rates were friction and pumping capabilities. Table 1 showed the data of field study conducted for PWRI programme in a field in Gulf of Mexico.

From these studies, friction contributed significant part in PWRI performance which varied significantly depending on rate and tubing size. In addition, a number of other estimates were determined over a range of the variables of Young's Modulus, Poisson's Ratio, injection water temperature, and the difference in pressure between the reservoir pressure and flowing bottom hole pressure that were ran (Fig. 6).

\section{Impact of water quality on matrix injection}

The WID (Water Injectivity Decline) simulator results presented in Figs. 7 and 8 outlined the significance of water quality on injection rates and pressure. The simulator was developed at the University of Texas. The output shows injectivity vs. time. The injectivity is dimensionless permeability, and the half-life is the amount of time, in days, at which the dimensionless permeability drops to half the original value. The output based on their results shown in Fig. 7 is for matrix injection with very good water quality (1 ppm of 1 micron sized particles). The results show futility of trying to inject below the fracture gradient since injection rate declines in the matter of a few days to a fraction of the original value. The permeability profile shows that the damage is shallow, even with good perm (200 md).

The field data runs reviewed showed that water quality has a significant impact on the half-life. With $5 \mathrm{ppm}$ of 5 micron solids, the half-life is about a year for a $100^{\prime}$ fracture. This meant that the fracture will continue to grow at about this rate every year, assuming that it is confined to a single zone (Tables 2, 3).

\section{Results and discussions}

The discussions of results of findings are presented as follows:

\section{Injectivity profile with time}

In this section, the results of injectivity with time are presented for two different studies obtained for two different 
Fig. 6 Flow chart algorithm of simulation program for the PWRI model

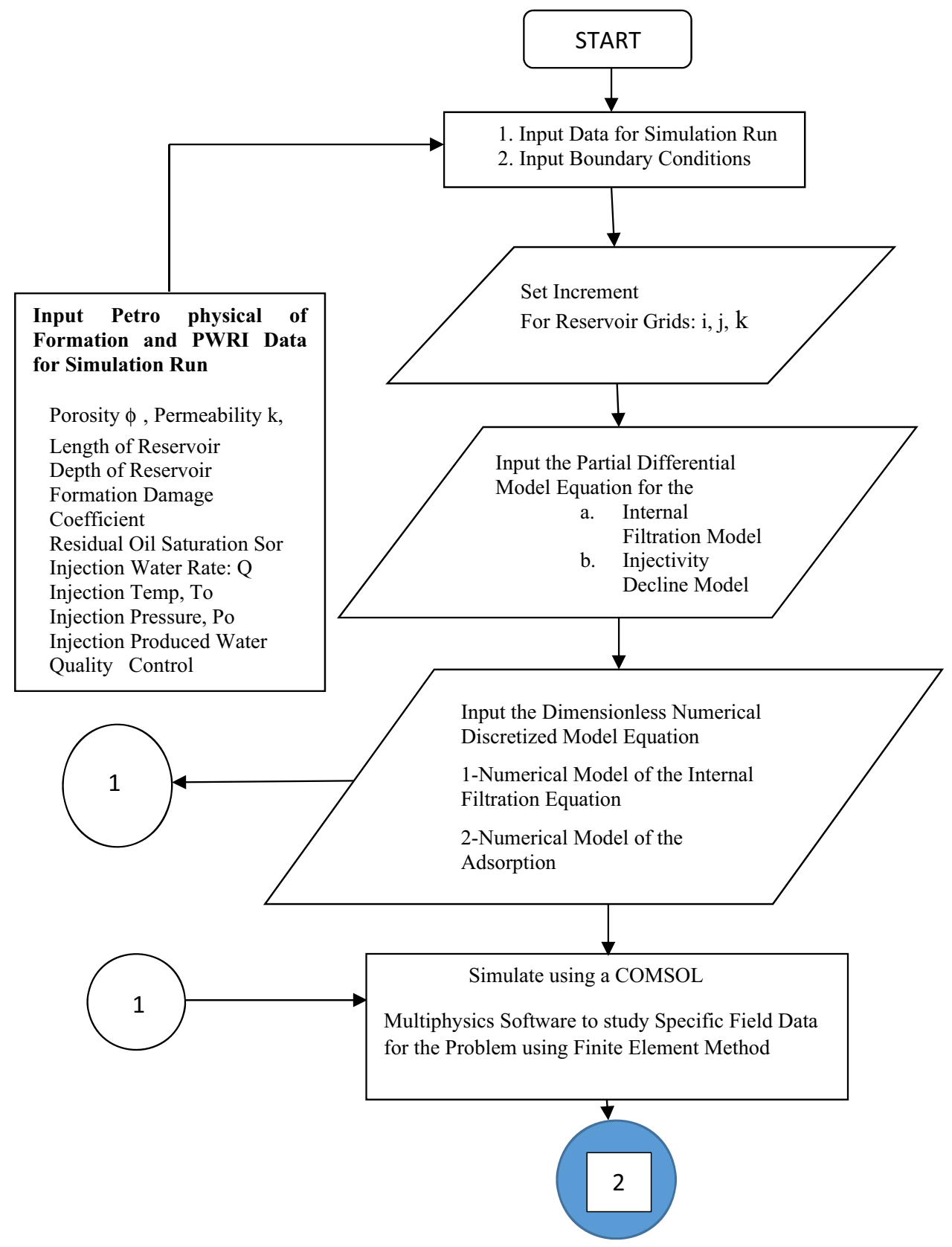

fields, with the actual field data run compared with simulated data obtained from this work. Figure 9 results show plot of injectivity with time for a typical PWRI data obtained for a field in the Gulf of Mexico (Texas Fields) and were supplied by the field operator, while Fig. 10 shows the simulated injectivity based on data obtained from operator Nigerian Oil Field. While the numerical values of the simulated and field study may differ, injectivity profile trends obtained in Fig. 9 compared favorably with injectivity obtained in Fig. 10 simulated on the COMSOL Multiphysics platform thereby validating the improved PWRI model. The plots establish that injectivity decline was spatially away from the produced water invasion zone in the host aquifer to settle at a threshold value. The transition time to cake formation for actual field run was 50 days while for our simulated run was observed to occur within 5 days. The blue line shown in Fig. 9 shows the injectivity decline for the field studies, while the grey line in Fig. 10 shows the injectivity decline profile simulated in COMSOL metaphysics environment where a correlation in trend was observed. The green line in Fig. 9 shows a steep change in injectivity near the well bore showing effect of geometry with respect to injection fracture with injection decline steepest at the well bore than further away. 


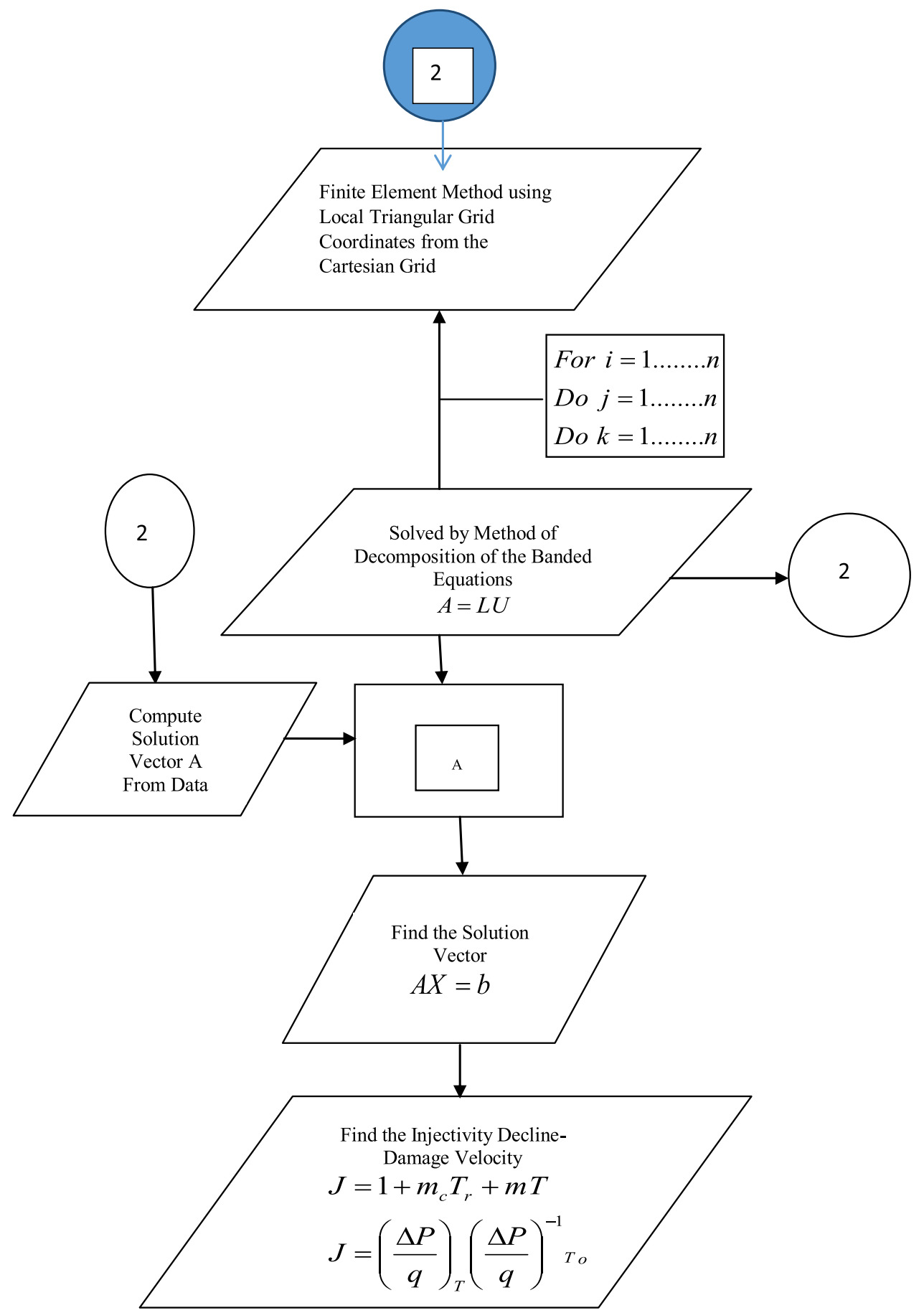

Fig. 6 continued

\section{Effect of flow rate on injectivity with time}

In this section, we show how higher injection rate and sweep volume could impact on injectivity decline and cake deposition. Figures 11 and 12 show the plots of the simulated injectivity decline against PWRI rates and observed to be inversely proportional to each other. From plots increased injection rate led to decreased injectivity decline leading to sustained impairment and transition to cake formation which was minimized to a constant residual value. The sweep volume erodes deposition and adsorption on walls of aquifer, because drag force was 
Fig. 71 ppm, 1 micron, Injectivity and perm profiles *source: Energy Tech Co, Houston, Texas, USA and petroleum regulator, Department of Petroleum Resources (DPR), as reported by (Idialu 2014)
Injectivity

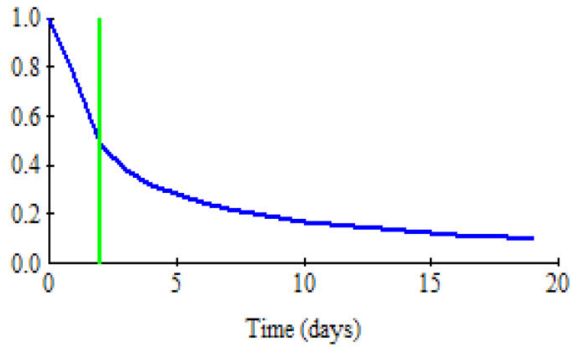

Permeability Profile at 2 days

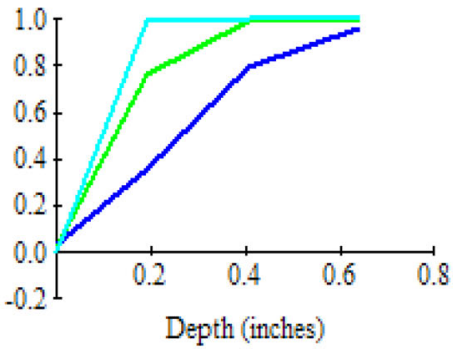

1 good

$2 \mathrm{ok}$

3 poor

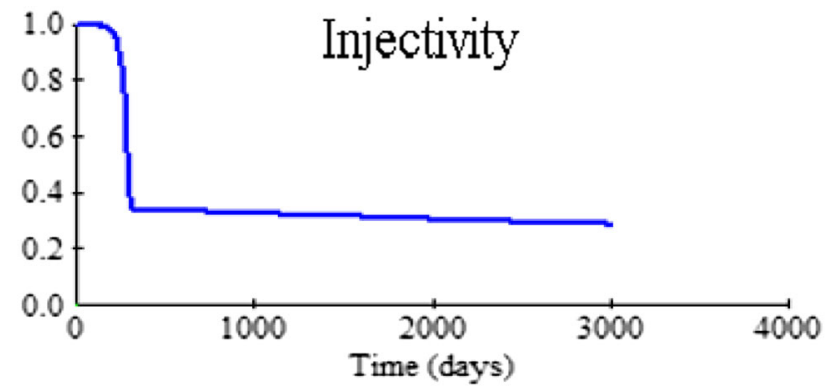

Fig. $860 \mathrm{md}, 100 \mathrm{ft}$ fracture, $5 \mathrm{ppm}, 5$ micron *source: Energy Tech Co, Houston, Texas, USA and petroleum regulator, Department of Petroleum Resources (DPR), as reported by (Idialu 2014)

observed to have the effect of reducing solids deposition to a constant injection rate. Previous studies showed that friction contributed significant role in PWRI performance and varied significantly depending on rate and tubing size.
Significant reduction in injectivity decline and fracturing could be attributed to lager drag force resulting from increased rates. These results were validated by Gulf of Mexico study presented in Table 1 where similar observations of plots of actual and simulated results trends were correlated. In addition, a number of other estimates over a range of the variables of Young's Modulus, Poisson's Ratio, injection water temperature, and the difference in pressure between the reservoir pressure and flowing bottom hole pressure were ran. The results in Fig. 11 showed futility of attempting to inject below the fracture gradient since injection rate declines in the matter of a few days to a fraction of the original value transient was followed by a steady state of constant injectivity beyond which decline remains constant after 15 days, transition time to cake formation irrespective of the injection rates. Injectivity decline increased as flow rate

Table 2 Sensitivity summary data *source: Energy Tech Co, Houston, Texas, USA and petroleum regulator, Department of Petroleum Resources (DPR), as reported by (Idialu 2014)

\begin{tabular}{|c|c|c|c|c|c|c|c|}
\hline & Frac gradient & WHP & Young's modulus & Poisson's ratio & Injection temp & BHP $-P_{\mathrm{r}}$ injection & Friction \\
\hline Best guess & 0.60 & 2.545 & $2,500,000$ & 0.1 & 80 & 2000 & 900 \\
\hline Highest pressure & 0.70 & 4.603 & $2,000,000$ & 0.08 & 150 & 2500 & 1500 \\
\hline Lowest pressure & 0.49 & 1.134 & $3,000,000$ & 0.125 & 60 & 1500 & 600 \\
\hline Best guess & 0.60 & 2.545 & $2,500,000$ & 0.1 & 80 & 2000 & 900 \\
\hline YM high & 0.56 & 2.140 & $3,000,000$ & 0.1 & 80 & 2000 & 900 \\
\hline YM low & 0.64 & 2.950 & $2,000,000$ & 0.1 & 80 & 2000 & 900 \\
\hline Best guess & 0.60 & 2.545 & $2,500,000$ & 0.1 & 80 & 2000 & 900 \\
\hline PR high & 0.60 & 2.487 & $2,500,000$ & 0.125 & 80 & 2000 & 900 \\
\hline PR low & 0.60 & 2.589 & $2,500,000$ & 0.08 & 80 & 2000 & 900 \\
\hline Best guess & 0.60 & 2.545 & $2,500,000$ & 0.1 & 80 & 2000 & 900 \\
\hline Temp high & 0.68 & 3.379 & $2,500,000$ & 0.1 & 150 & 2000 & 900 \\
\hline Temp low & 0.57 & 2.307 & $2,500,000$ & 0.1 & 60 & 2000 & 900 \\
\hline Best guess & 0.60 & 2.545 & $2,500,000$ & 0.1 & 80 & 2000 & 900 \\
\hline Press high & 0.63 & 2.901 & $2,500,000$ & 0.1 & 80 & 2500 & 900 \\
\hline Press low & 0.56 & 2.190 & $2,500,000$ & 0.1 & 80 & 1500 & 900 \\
\hline Best guess & 0.60 & 2.545 & $2,500,000$ & 0.1 & 80 & 2000 & 900 \\
\hline Friction high & 0.60 & 3.145 & $2,500,000$ & 0.1 & 80 & 2000 & 1500 \\
\hline Friction low & 0.60 & 2.245 & $2,500,000$ & 0.1 & 80 & 2000 & 600 \\
\hline
\end{tabular}


decreases and vice versa. Formation around the fracture is impaired by deep penetration of solids, (ii) an external filter cake is built on the fracture wall by oil and solids

Table 3 WID run summary *source: Energy Tech Co, Houston, Texas, USA and petroleum regulator, Department of Petroleum Resources (DPR), as reported by (Idialu 2014)

\begin{tabular}{lllll}
\hline Perm & $\begin{array}{l}\text { Particle size, } \\
\text { microns }\end{array}$ & $\begin{array}{l}\text { Concentration, } \\
\mathrm{ppm}\end{array}$ & $\begin{array}{l}\text { Half-life, } \\
\text { days }\end{array}$ & $\begin{array}{l}\text { Frac Length, } \\
\mathrm{ft}\end{array}$ \\
\hline $\begin{array}{l}\text { All three } \\
\text { zones }\end{array}$ & 1 & 1 & 2 & $\begin{array}{c}\text { (matrix } \\
\text { injection) }\end{array}$ \\
200 & 5 & 5 & 152 & 50 \\
200 & 2 & 2 & 381 & 50 \\
200 & 1 & 1 & 766 & 50 \\
60 & 5 & 5 & 298 & 100 \\
60 & 5 & 5 & 155 & 50 \\
60 & 2 & 2 & 385 & 50 \\
60 & 1 & 1 & 770 & 50 \\
5 & 2 & 2 & 403 & 50 \\
5 & 1 & 1 & 790 & 50 \\
\hline
\end{tabular}

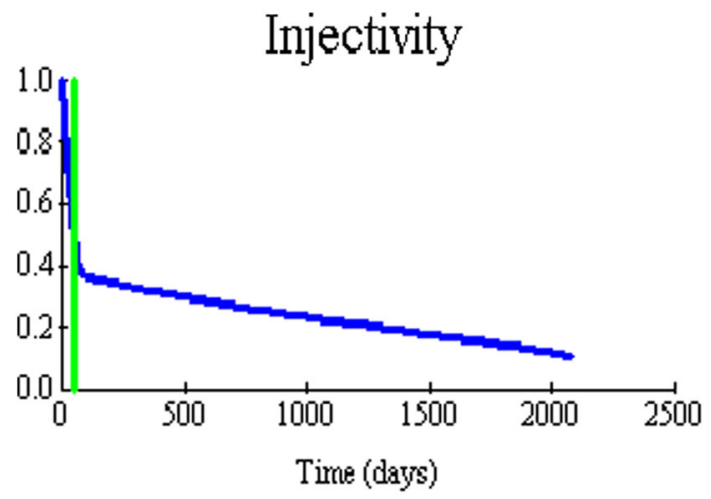

Fig. 9 Field studies, injectivity with time that remain in the fracture and (iii) filter cake growth eventually leads to plugging of the fracture. The injectivity decline was dependent on injection rate impact on produced water invasion zone flooding volume in aquifer formation with a lower sweep volume leading to higher injectivity decline and in increase of the produced water sweep volume rate leads to higher injectivity performance and, therefore, higher recovery.

\section{Effect of particle size and formation damage on injectivity}

In this section, the effects of particle size on injectivity with time were studied and demonstrated. Figure 13 showed decrease in injectivity with time as the particle size decreases. The particle to grain size $\left(\frac{\mathrm{d} p}{\mathrm{~d}_{g}}\right)$ of 0.6164 showed lower injectivity decline than a particle to grain size $\left(\frac{\mathrm{d} p}{\mathrm{~d} g}\right)$ of 0.2740 . The smaller particles were able to penetrate the pores faster than larger grain particles in suspended solids thereby increasing chances for internal cake formation and external cake build up. The plots showed that injectivity index decreased from 1.135 to 1.1 in 30 days. The impact of particle to grain size is a function of adsorption capacity of particles on aquifer wall to form cake deposits significant in altering injectivity and formation damage alongside quality of constituents, injection rate of produced water which were established in the previous section.

Figure 14 outlined the variation of injectivity decline with velocity damage factor. The plots showed decreased injectivity as damage factor increased irrespective of time the produced water is transported in the reservoir. The damage factor is a numerical index of the reduction in permeability resulted from formation damage due to
Fig. 10 Injectivity profile with time (days)

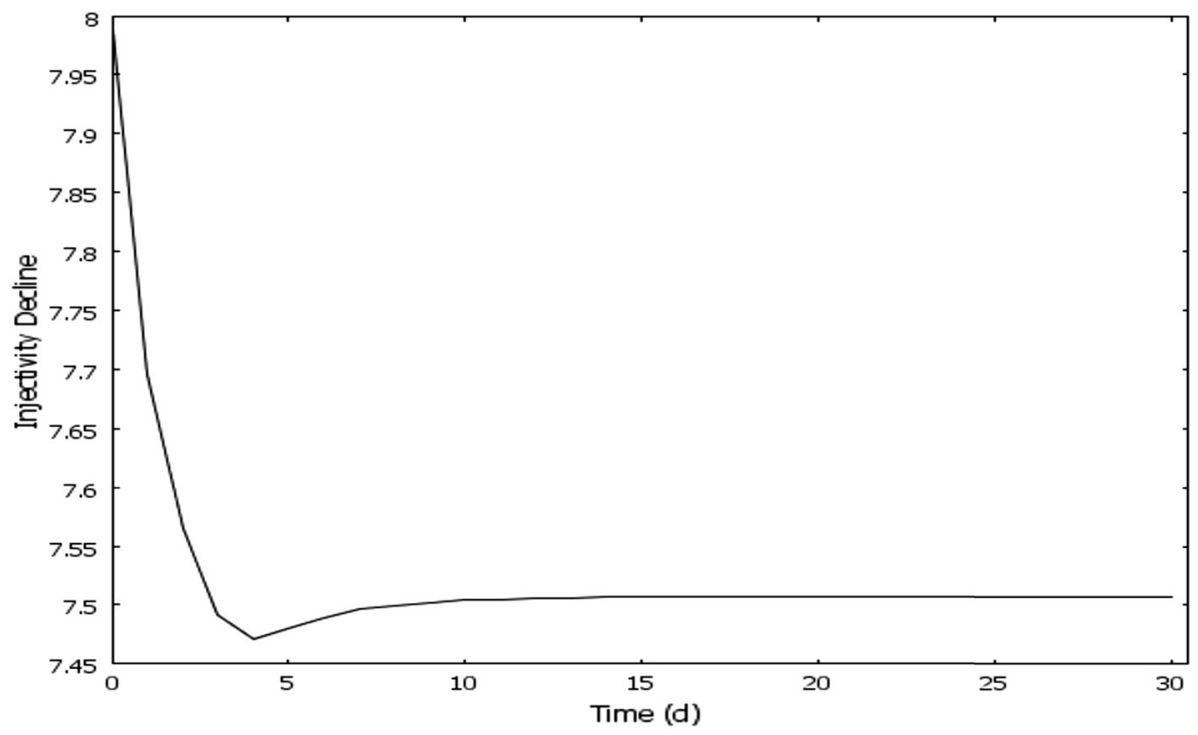


Fig. 11 Effect of flow rate on injectivity
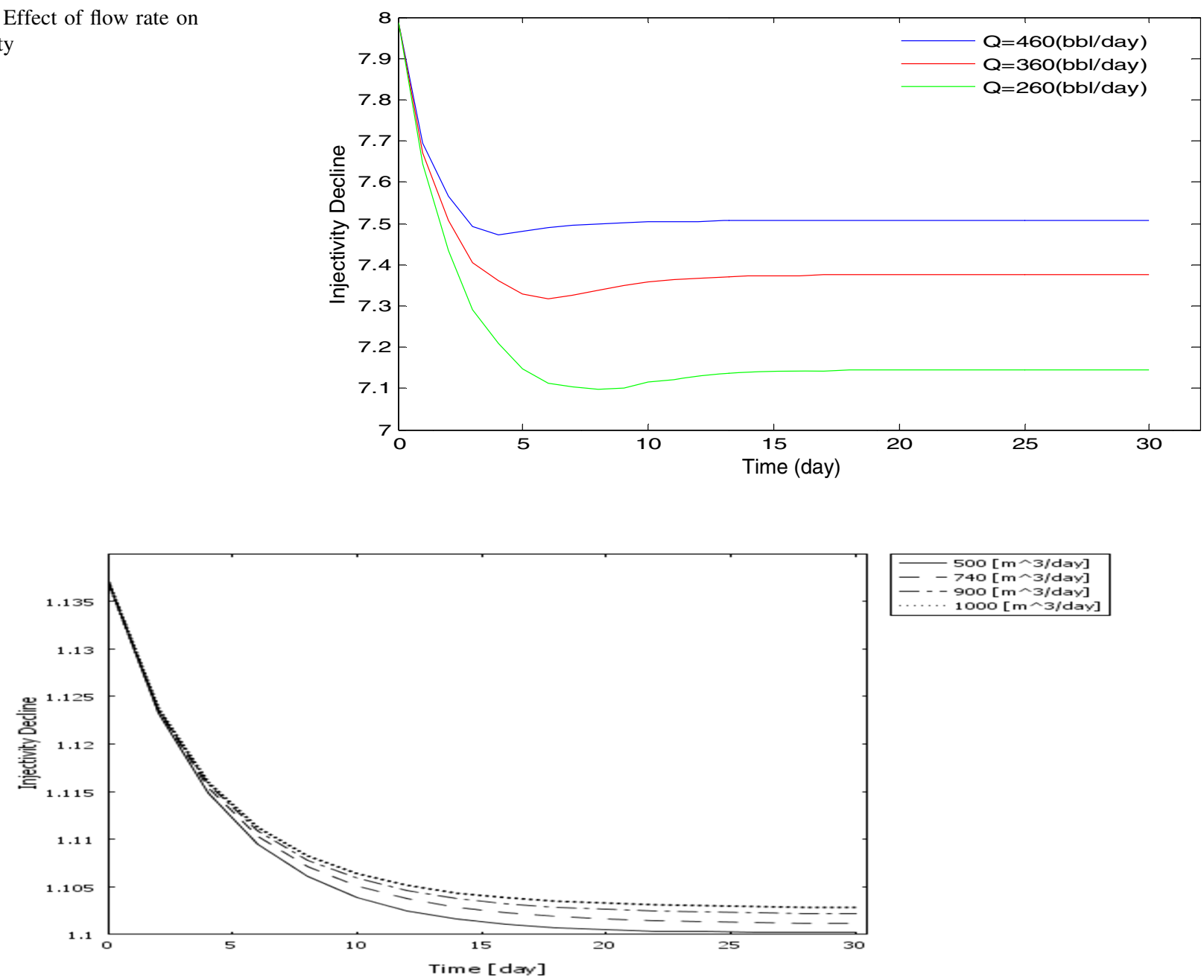

Fig. 12 Injectivity against time and flow rate. $\left(\frac{\mathrm{d} p}{\mathrm{~d} g}\right)$ is the particle to grain ratio

scaling. However, the extent of decline of injectivity with damage factor was observed to invariant with time. The injectivity was same irrespective of the time for any specific damage factor.

\section{Profile of permeability damage with distance}

Figure 15 showed the profile of permeability on both fracturing and filtration phenomena. The profile decreased with time and increased uniformly with radial distance from produced water invasion zone. From the analysis of the results in the absence of particle deposition, low permeability formation were observed to be more likely fractured as the net fracturing pressure was observed to be inversely proportional to permeability, for a given injection rate. In addition, particle filtration and formation damage were governed by the interactions of particles in the injected water within the reservoir. In general, formation plugging is severe as the formation permeability decreased.
However, from results, formation permeability was directly dependent on the formation grain size (dg). A comparison of the profile in Fig. 16 and the permeability of field data of Fig. 15 showed a good agreement for damage permeability, with a little allowance for lithological variation and other factors that may partially contribute to injectivity variation.

\section{Effect of temperature variation on injectivity with time}

Figure 17 outlines the significance of temperature variation as a key role in adsorption rate in the Arrhenius equation and subsequently injectivity decline. Higher temperature favors greater retention rates outlining the importance of adsorption rate in particle deposition. The fracture gradient was influenced as temperature changes which led to less injectivity as temperature increases. As cooler injection fluids reduce temperature, the rock becomes more brittle 
Fig. 13 Effect of particle size on injectivity with time. $d p / d g$ is the particle to grain ratio

Fig. 14 Variation of injectivity decline with damage factor
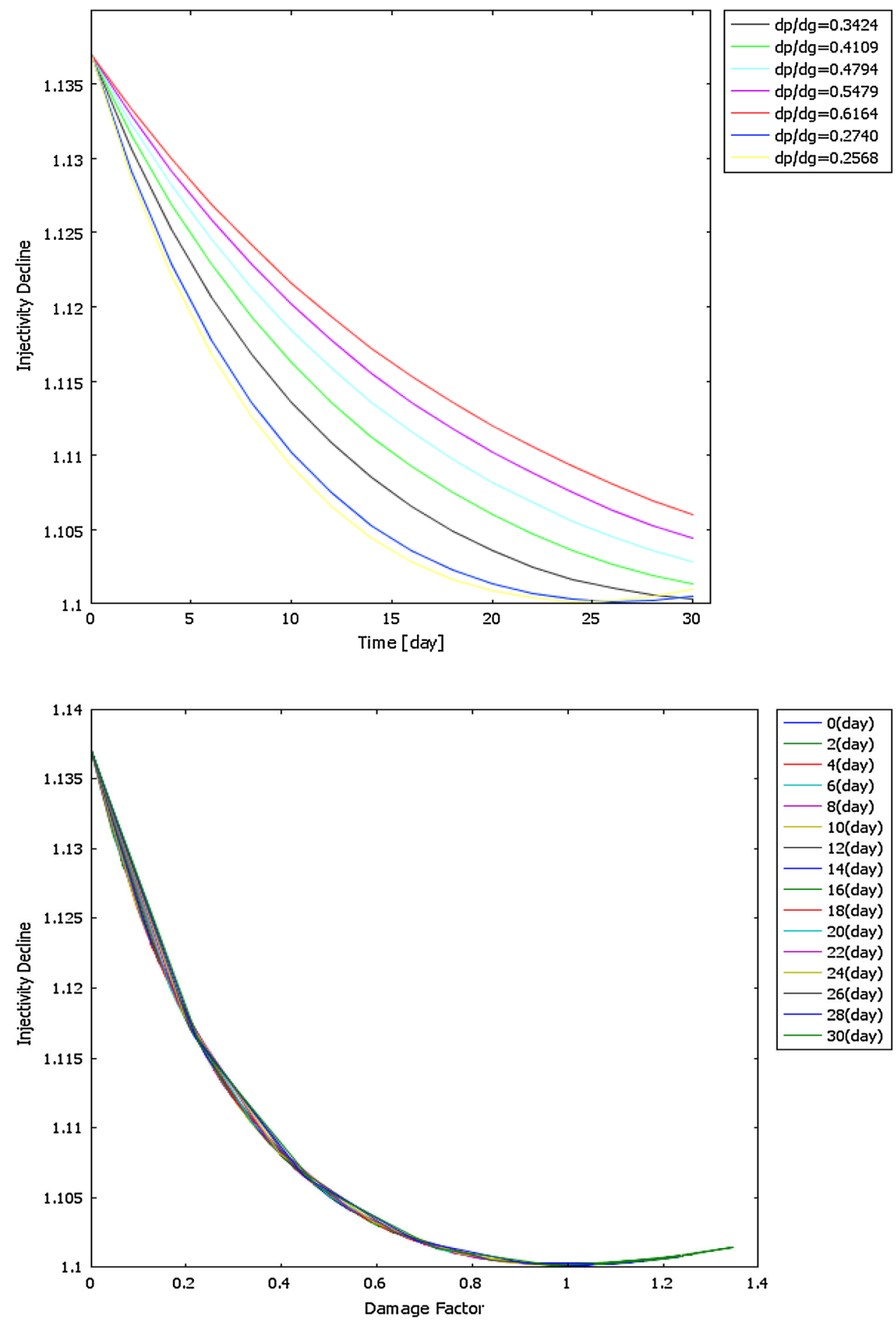

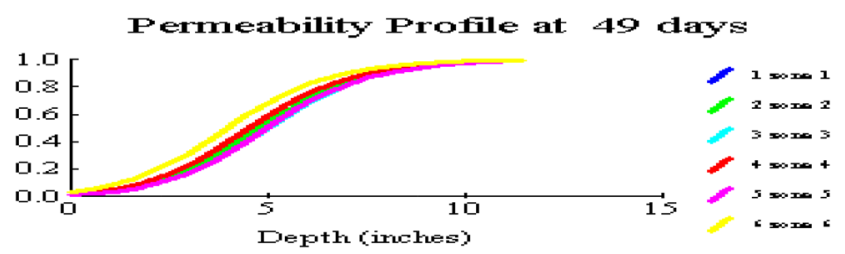

Fig. 15 Field simulation data of profile of permeability with depth at different zones and this effect is strongly dependent on Young's Modulus of elasticity. The profile is an exponential decrease in injectivity with time as temperature decreases.

\section{Concentration variation with depth for first 5 days}

Figure 18 showed the concentration of suspended and deposited solids decreases exponentially with depth. At an 
Fig. 16 Profile of permeability damage with distance
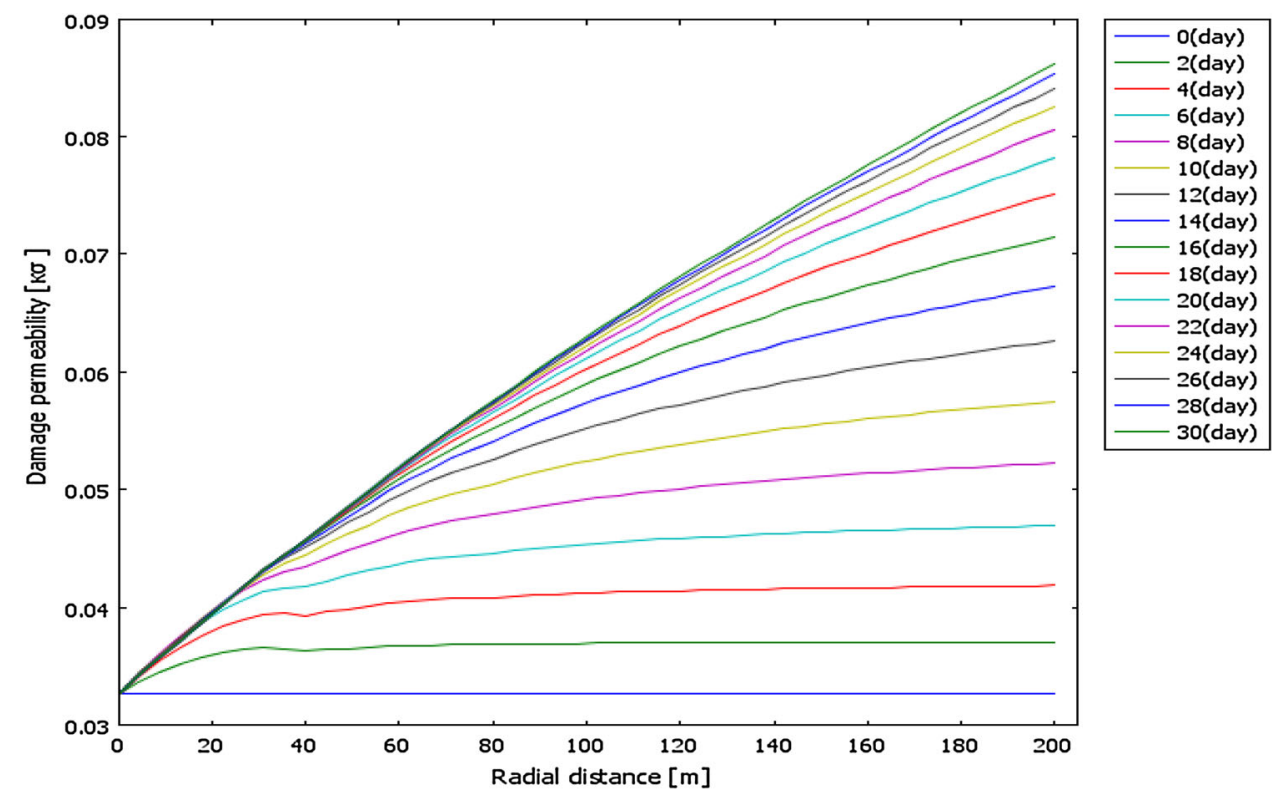
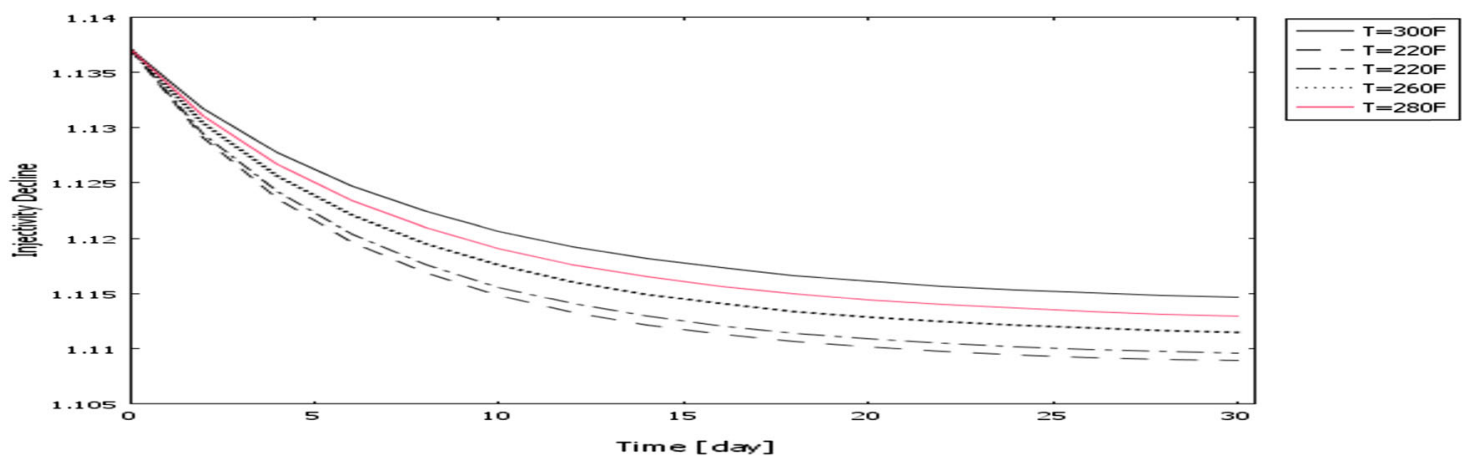

Fig. 17 Effect of temperature variation on injectivity with time

Fig. 18 Variation of concentration (suspended and deposited solids) with time for the first 5 days, of injection for calcite geochemical reaction index $\mathrm{SI}=1.48$

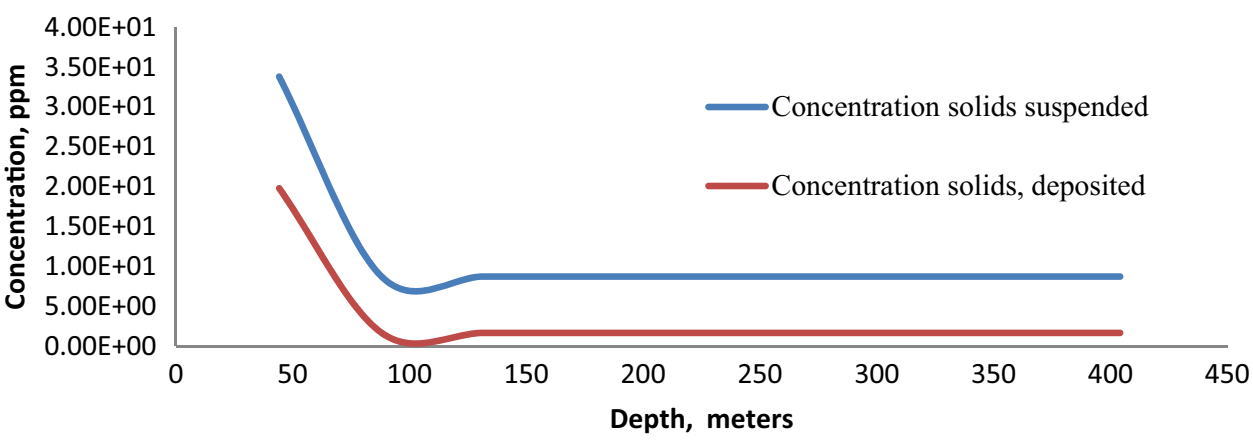

assumed depth $100 \mathrm{~m}$, the concentration decrease reaches a minimum after which concentration remains constant. The effect of geochemical reaction scaling is apparent as concentration solids deposited was observed to be less than concentration in suspension.

Figure 19 outlines simulation of injectivity performance with time for the reservoir temperature temp $=164{ }^{\circ} \mathrm{F}$ and Flow Line temp $=125^{\circ} \mathrm{F}$ for calcite geochemical reaction which has a scaling index $\mathrm{SI}=1.48$. The significant results reveal Injectivity decline is exponential in time. For a water injection rate of 5000 bbls/day, injectivity decline is a maximum on the first day and remain constant for the remaining days as it progresses. The simulation results show potential calcite scaling of $\mathrm{SI}=1.48>1$ induces a faster time to injectivity decline. 
Fig. 19 Profile of injectivity with time for reservoir temp $=164^{\circ} \mathrm{F}$ and flow line temp $=125^{\circ} \mathrm{F}$ for calcite geochemical reaction index $\mathrm{SI}=1.48$
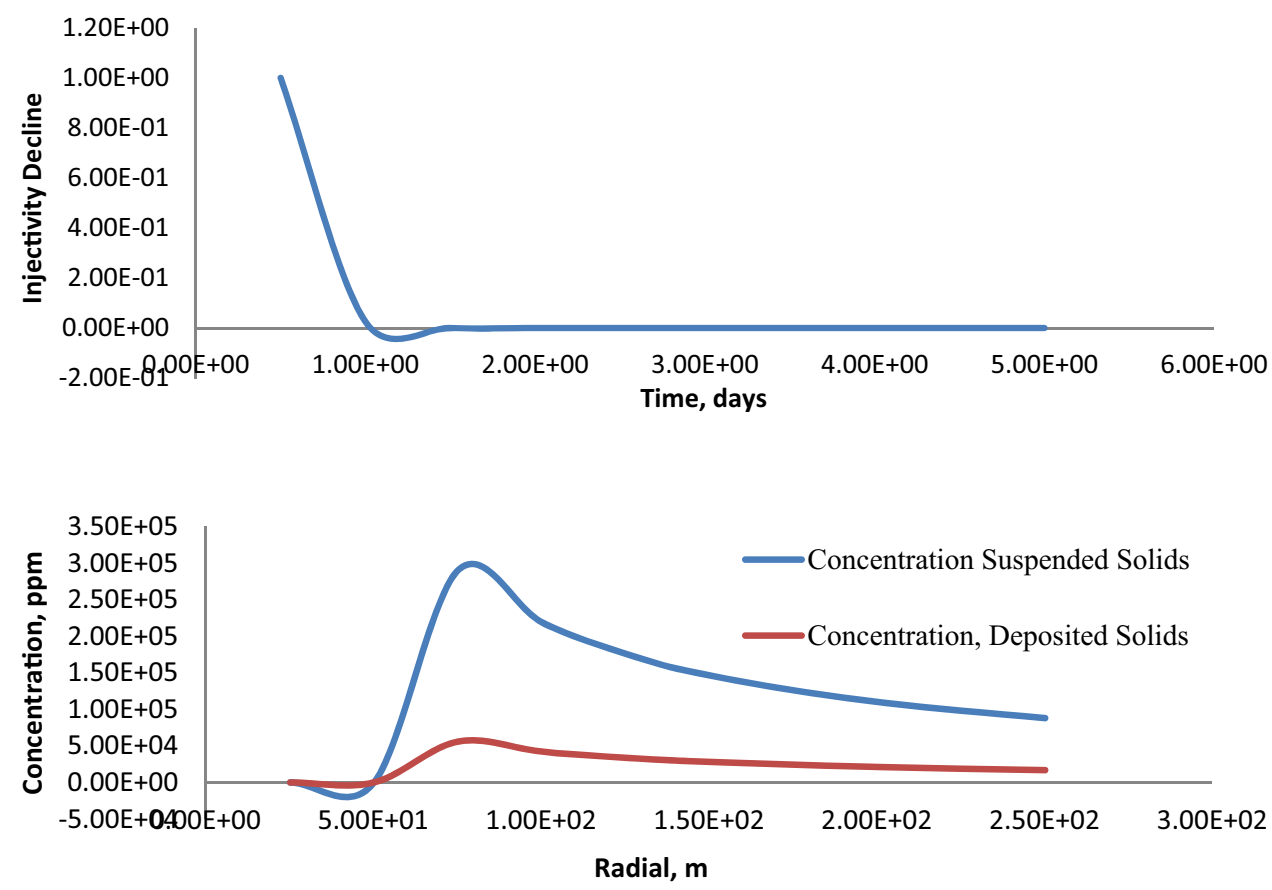

Figure 20 is the profile of concentration of suspended and deposited solids with radial distance on the 5th day for injection at $5000 \mathrm{bbl} /$ day (TVD $44.2 \mathrm{~m}$ and time 1 day) for reservoir temp $=164{ }^{\circ} \mathrm{F}$ and flow line temp $=125^{\circ} \mathrm{F}$ for Calcite Scaling Index SI $=1.48$. Concentration decreases for deposited and suspended solids after 50-100 m may be the result of increased deposition precipitated due to increased geochemical scaling.

\section{Conclusion}

An improved PWRI model incorporating the effect of geochemical reaction, adsorption kinetics and hydrodynamics molecular transport was presented to predict performance of produced water reinjection Schemes in hydrocarbon aquifer. The model was solved using a finite-element method with the injectivity and solids deposition simulated in COMSOL Multiphysics Software. At a specific length in the aquifer, the concentration profile of the active specie follows an exponential distribution in time. Meanwhile, injectivity decline decreases exponentially with radial distance in the aquifer. The injectivity decline was found to be a function of cake deposition resulting from geochemical reaction, adsorption kinetics coupled filtration scheme and molecular diffusion. In conclusion, we established that the transition time $t_{\mathrm{r}}$ to cake nucleation and growth was a consequence aquifer capacity, filtration coefficients particle and grain size diameters and, more importantly, adsorption kinetics, geochemical reaction and produced water quality.

Acknowledgements The support for this work by the Energy Tech Co, Houston Texas and Department of Petroleum Resources for supplying research data is greatly acknowledged. The support of systems engineering staff and technical and research assistant at the department of chemical engineering is acknowledged for their assistance in COMSOL multiphysics software programming of data and models.

Open Access This article is distributed under the terms of the Creative Commons Attribution 4.0 International License (http:// creativecommons.org/licenses/by/4.0/), which permits unrestricted use, distribution, and reproduction in any medium, provided you give appropriate credit to the original author(s) and the source, provide a link to the Creative Commons license, and indicate if changes were made.

\section{Appendix A: field validation simulation on nigerian onshore field}

The field data for the study was supplied by the operator of the onshore field (Field $\mathrm{X}$ ) in Nigeria Licensed by the Regulator is presented below (Tables 4, 5). 
Table 4 Reservoir/well data of sample of study area

\begin{tabular}{|c|c|c|c|c|c|c|c|}
\hline Sample name & Units & FieldX-10ST & Field X-12HST & Field X-13HST & Field X-18ST & Field X-26 & $\begin{array}{l}\text { Field } X \\
\text { produced water }\end{array}$ \\
\hline Data sampled & & & & & & & $20 / 3 / 08$ \\
\hline Analysis & & VRMT & VRMT & & VRMT & VRMT & VRMT \\
\hline Field & & $X$ & $X$ & & $X$ & $X$ & Produced Water \\
\hline Well & & 10 & 12 & 13 & 18 & 26 & \\
\hline Reservoir & & R-03/X-02 & R-03/X-05 & $\mathrm{R}-03 / \mathrm{X}-06$ & R-17/X-06 & $\mathrm{R}-03 / \mathrm{X}-06$ & \\
\hline Interval (TVD) & (ft) & $8709-10164$ & $7702-9385$ & $7310-8510$ & $7282-7340$ & $5891-5890$ & \\
\hline Datum & (ft) & 6026 & 5898 & 5897 & 7296 & 5880 & \\
\hline Initial reservoir pressure & Psia & 2457 & 2571 & 2546 & 2913 & 2534 & $\mathrm{n} / \mathrm{a}$ \\
\hline Initial reservoir temperature & ${ }^{\circ} \mathrm{F}$ & 164 & 163 & 162 & 188.75 & 162 & $\mathrm{n} / \mathrm{a}$ \\
\hline Flow line pressure & Psia & 105 & 120 & 125 & 450 & 125 & $\mathrm{n} / \mathrm{a}$ \\
\hline Flow line temperature & ${ }^{\circ} \mathrm{F}$ & 124 & 122 & 119 & 128 & 120 & $\mathrm{n} / \mathrm{a}$ \\
\hline Average gas production & MScf/d & 1309 & 1433 & 510 & 778 & 294 & $\mathrm{n} / \mathrm{a}$ \\
\hline Average oil production & bbl/day & 1740 & 2600 & 1623 & 1501 & 940 & $\mathrm{n} / \mathrm{a}$ \\
\hline Average water production & bbl/day & 2.0 & 2.7 & 405 & 0.5 & 1.0 & $\mathrm{n} / \mathrm{a}$ \\
\hline
\end{tabular}

Table 5 Produced water parameters quality

\begin{tabular}{|c|c|c|c|c|c|c|c|}
\hline Parameters & Symbol & FieldX-10ST & Field X-12HST & Field X-13HST & Field X-18ST & Field X-26 & $\begin{array}{l}\text { Field } \mathrm{X} \\
\text { produced water }\end{array}$ \\
\hline \multicolumn{8}{|l|}{$\mathrm{pH}$} \\
\hline Density & $\mathrm{g} / \mathrm{cc}$ & 8.37 & 8.64 & 8.40 & 8.41 & 8.43 & 7.95 \\
\hline Total dissolved solid & $\mathrm{mg} / \mathrm{l}$ & $15,050.00$ & 9640.00 & $12,720.00$ & $14,720.00$ & $12,680.00$ & $16,000.00$ \\
\hline Chloride & $\mathrm{mg} / \mathrm{l}$ & 9996.9 & 6797.89 & 9447.07 & 9597.02 & 8797.27 & 10946.00 \\
\hline Sulphate & $\mathrm{mg} / \mathrm{l}$ & 124.55 & 80.68 & 104.82 & 130.80 & 94.22 & 39.12 \\
\hline Total alkalinity & $\mathrm{mg} / \mathrm{l}$ & 900.00 & 560.00 & 1633.33 & 833.33 & 833.33 & 1520 \\
\hline Sodium & $\mathrm{mg} / \mathrm{l}$ & 7251.72 & 4996.41 & 6163.06 & 7410.69 & 6188.79 & 2773.02 \\
\hline Potassium & $\mathrm{mg} / \mathrm{l}$ & 198.75 & 148.56 & 213.51 & 221.80 & 179.96 & 104.10 \\
\hline Calcuim & $\mathrm{mg} / \mathrm{l}$ & 43.50 & 46.40 & 64.60 & 51.60 & 106.00 & 303.25 \\
\hline Magnesium & $\mathrm{mg} / \mathrm{l}$ & 27.50 & 25.60 & 37.80 & 36.00 & 26.00 & 51.12 \\
\hline Strontium & $\mathrm{mg} / \mathrm{l}$ & 0.20 & 0.24 & 0.33 & 0.36 & 26.00 & 51.12 \\
\hline Barium & $\mathrm{mg} / \mathrm{l}$ & 1.55 & 1.76 & 2.01 & 2.12 & 1.48 & 1.32 \\
\hline Iron & $\mathrm{mg} / \mathrm{l}$ & 0.84 & 0.13 & 0.03 & 0.31 & 0.21 & 0.86 \\
\hline Carbonate & $\mathrm{mg} / \mathrm{l}$ & 240 & 96 & 320 & 80 & 160 & 0.00 \\
\hline Bicarbonate & $\mathrm{mg} / \mathrm{l}$ & 610 & 488 & 1342 & 854 & 692.33 & 1854 \\
\hline Phosphate & $\mathrm{mg} / \mathrm{l}$ & 4.55 & 3.84 & 8.68 & 2.96 & 1.80 & \\
\hline Hydroxide & $\mathrm{mg} / \mathrm{l}$ & 0.00 & 0.00 & 0.00 & 0.00 & 0.00 & 0.00 \\
\hline Copper & $\mathrm{mg} / \mathrm{l}$ & 0.07 & 0.00 & 0.12 & 0.84 & 0.36 & \\
\hline Nickel & $\mathrm{mg} / \mathrm{l}$ & 0.14 & 0.10 & 0.17 & 0.12 & 0.04 & \\
\hline Lead & $\mathrm{mg} / \mathrm{l}$ & 0.00 & 0.00 & 0.00 & 0.00 & 0.00 & 0.00 \\
\hline Zinc & $\mathrm{mg} / \mathrm{l}$ & 0.28 & 0.11 & 0.03 & 0.03 & 0.07 & 2.37 \\
\hline \multicolumn{8}{|l|}{ Quality control } \\
\hline Total dissolved solids-calculated & $\mathrm{mg} / \mathrm{l}$ & 17,966 & 12,362 & 16,730 & 17,891 & 15,751 & $13,418.00$ \\
\hline SP Gravity-calculated & $\mathrm{g} / \mathrm{cc}$ & 1.012 & 1.009 & 1.012 & 1.012 & 1.011 & 1.007 \\
\hline
\end{tabular}


Table 6 Produced water injectivity quality

\begin{tabular}{|c|c|c|c|c|c|c|c|}
\hline \multirow{3}{*}{$\begin{array}{l}\text { Well(s) } \\
\text { Tempt. } \\
{ }^{\circ} \mathrm{F}\end{array}$} & \multicolumn{5}{|l|}{ X10ST } & \multirow{3}{*}{$\begin{array}{l}\text { Inhibitor } \\
\mathrm{mg} / \mathrm{L}\end{array}$} & \multirow[t]{3}{*}{$\mathrm{pH}$ after precipitation } \\
\hline & \multirow{2}{*}{$\begin{array}{l}\text { Press. } \\
\text { Psia }\end{array}$} & \multicolumn{4}{|c|}{ Calcite } & & \\
\hline & & $\mathrm{pH}$ & SI & $\Delta \mathrm{SI}$ & $\mathrm{mg} / \mathrm{L}$ & & \\
\hline 124 & 105 & 8.50 & 1.48 & 0.63 & 104 & 0.35 & 8.45 \\
\hline 128 & 366 & 8.08 & 1.12 & 0.27 & 98 & 0.05 & 8.03 \\
\hline 133 & 628 & 7.93 & 0.99 & 0.14 & 95 & 0.00 & 7.88 \\
\hline 137 & 889 & 7.85 & 0.92 & 0.07 & 93 & 0.00 & 7.81 \\
\hline 142 & 1,150 & 7.80 & 0.88 & 0.03 & 91 & 0.00 & 7.76 \\
\hline 146 & 1412 & 7.77 & 0.86 & 0.01 & 90 & 0.00 & 7.73 \\
\hline 151 & 1673 & 7.75 & 0.85 & 0.00 & 90 & 0.00 & 7.71 \\
\hline 155 & 1934 & 7.74 & 0.85 & 0.00 & 90 & 0.00 & 7.70 \\
\hline 160 & 2196 & 7.74 & 0.85 & 0.00 & 90 & 0.00 & 7.69 \\
\hline 164 & 2457 & 7.73 & 0.85 & 0.00 & 90 & 0.00 & 7.69 \\
\hline
\end{tabular}

\section{Produced water analysis data}

The water analysis data conducted at a Laboratory in Lagos is presented in the Table 6. The chemical indicators for QA/QC, such as $\mathrm{Na} / \mathrm{K}, \mathrm{Ca} / \mathrm{Mg}, \mathrm{Ca} / \mathrm{Na}$ and $\mathrm{TDS}$, are within ranges typical of formation waters. Several software programs have been used to calculate the scaling potential. The program ScaleSoftpitzer by Mason Thompson's Brine Consortia Group at Rice University reported used for all scaling tendency calculations. The program was designed for the prediction, treatment and control of common scale deposits in Oil and Gas wells. Scale SoftPitzer quantitatively calculates the scaling potential up the wellbores. It used the formation water compositions, $\mathrm{CO}_{2}$ and $\mathrm{H}_{2} \mathrm{~S}$ content of the gas compositions or $\mathrm{pH}$ and the production rate data if available. The scaling potential is expressed in terms of saturation indices (SI) for scale minerals and the amount of scale deposits per volume of water in $\mathrm{mg} / \mathrm{l}$.

Saturation Index (SI) is defined as log of saturation ratio as shown below

$\mathrm{SI}=\log \left(\left(\mathrm{CaCO}_{3}\right) / K_{\mathrm{sp}}\right)$

$K_{\text {sp }}$ is the solubility product of calcium carbonate.

Please note:

If $\mathrm{SI} \leq 0 \quad$ No Scale formation should be expected.

If $\mathrm{SI} \geq 0 \quad$ There is potential for Scale Formation

\section{Field X-10ST}

Self scaling Assessment-Calcite

Without commingling with field $\mathrm{X}$ produced water, Well X-10RST shows the tendency to form calcite scale at production conditions.

The field for study was based on data for an onshore field in Nigeria overseen by the Petroleum Regulator and National Oil Company. Without Commingling with Field
$\mathrm{X}$ produced water, Well $\mathrm{X}-10 \mathrm{RST}$ shows the tendency to form calcite scale at production conditions.

\section{Model field study computer simulation analysis}

The classical model developed for PWRI was solved by finite-element method in COMSOL multiphysics software environment using the field data presented above for an onshore field in Nigeria. The produced water from the Field $\mathrm{X}$ is planned for water flood for enhanced hydrocarbon recovery. Five produced water samples were collected for this study. The samples were from FieldX10st, Field X12st, FieldX13st, FieldX14st and Field X14t. Their corresponding reservoirs are R-03/X-02, R-03/X-05, R-03/X06, $\mathrm{R} 17 / \mathrm{X}-06$ and $\mathrm{R}-03 / \mathrm{X}-06$, respectively. Water compatibility can be assessed by conducting the scaling tendencies predictions with respect to calcium carbonate (calcite) and barium Sulphate (Barite) of Field X produced water with formation water.

\section{Appendix B: The field data used for simulation is presented below}

Data

The chemical indicators for QA/QC such as $\mathrm{Na} / \mathrm{K}, \mathrm{Ca} /$ $\mathrm{Mg}, \mathrm{Ca} / \mathrm{Na}$ and $\mathrm{TDS}$ are within ranges typical of formation waters.

1) WELL 10 2) RESERVOIR B-03/X-02 3) INTERVAL (TVD) 8709-10164FT C

4) DATUM 6026 FT C 5) INITIAL RESERVOIR PRESSURE: 2457PSIA

6) INITIAL RESERVOIR TEMPERATURE: $164{ }^{\circ} \mathrm{C}$ FLOWLINE PRESSURE 105PSIA

OPEN (6, FILE = 'X.RES') 1) Initial Concentration of Deposits $\operatorname{CD}(1,1,1)=0.0,2)$ Time $=10$ days 3) 
Adsorption Constant Term KAD $=3.0 \mathrm{~mol} / \mathrm{dm}^{3} \mathrm{~s} \mathrm{3}$ ) Total Length of Reservoir $\mathrm{RN}=500 \mathrm{~m}$ 4) Mole Constant $\mathrm{RG}=8.3149 \mathrm{~kJ} / \mathrm{kmol} \mathrm{K}$ 4) Pressure Gradient $\mathrm{DP}=0.000005$ psia 5) Length of Damage Zone of Reservoir $\mathrm{RC}=200 \mathrm{~m}$ 6) Density of Particulate $=25 \mathrm{ppm} \mathrm{7)}$ Length of Well Bore $\mathrm{RW}=0.2 \mathrm{~m} \mathrm{8}$ ) Water Injection Rate $Q=5000$ bbls/day 9) Initial Concentration of Suspended Particulate $C O=25$ 10) Permeability Damage Constant $\mathrm{BDAMG}=50$ 11) Absolute Permeability KABS $=501 \mathrm{~m}$ Darcy 12) Relative Permeability of Water in Formation KROW $=0.5$ 13) Relative Permeability if Water-Oil KWOR $=0.5$ 14) DATUM Height TVD of formation $=6026 \mathrm{ft}$ 15) Total Vertical Depth TVD1 $=8709 \mathrm{ft}$ 16) Total Vertical Depth TVD2 $=10164 \mathrm{ft}$ 17) The Heat of Activation DHEA $=2.3 \mathrm{~J} / \mathrm{K}$ 18) Filtration Coefficient LAND $=20 /$ m 19) VISC $=0.7 \mathrm{cp} \mathrm{20)}$ Temperature of Formation TEMPF $=164^{\circ} \mathrm{F} \quad$ 21) Temperature of Reservoir TEMPR $=124^{\circ} \mathrm{F}$ 22) Flow Rate of Gas in Formation QGAS = $1309 \mathrm{MSfc} /$ days 23) Flow Rate of Water in Formation QWATER $=2.0$ bbls/days 24) Flow Rate of Oil in Formation QOIL $=1740$ bbls/days 25) Heat of Reaction Constant $\mathrm{L} 1=0.06345 \mathrm{~kJ} / \mathrm{Kmol} \mathrm{K}$ 26) Temperature Conversion to ${ }^{\circ} \mathrm{F}$ 27) $\mathrm{FTEMP}=(5.0 /$ 9.0 $)^{*}($ TEMPF-32) 28) RTEMP $=(5.0 / 9.0) *($ TEMPR-32 $)$ 29) $\mathrm{DTEMP}=$ RTEMP-FTEMP 30) TEMPD $=$ DTEMP/ LOG (RTEMP/FTEMP) 31) $\mathrm{KG}=\mathrm{L} 1 *$ EXP (-DHEA/ RG*TEMPD) 32) Grant Sites concentration $C T=1.0$ 33) Porosity of Reservoir, $P_{\text {or }}=0.22$ (33) Porosity of Cake, $P_{\text {orc }}=0.12$

Produced water re-injection data used in COMSOL multiphysics software Simulation

\begin{tabular}{ll}
\hline Variable & Values \\
\hline$c_{\mathrm{d}}$ & 0 \\
$k$ & $2 \mathrm{e}-3$ \\
$r_{\mathrm{w}}$ & 0.2 \\
$K_{\mathrm{or}}$ & 0.5 \\
$K_{\mathrm{abs}}$ & $50 \mathrm{e}-15$ \\
$K_{\mathrm{Q}}$ & 50 \\
$r_{\mathrm{e}}$ & 10 \\
$R_{\mathrm{g}}$ & 8.314 \\
$C_{\mathrm{T}}$ & 1 \\
$\mathrm{rho}$ & 25 \\
$\mathrm{DH}$ & 2.3 \\
$T$ & 346.483 \\
$C_{0}$ & 25 \\
$Q$ & 1360 \\
$v_{\text {is }}$ & 0.0007 \\
$A_{\mathrm{o}}$ & $2 \mathrm{e} 20$ \\
$k_{1}$ & $A_{\mathrm{o}} * \exp \left(-\mathrm{DH} /\left(R_{\mathrm{g}} * T\right)\right)$ \\
\hline
\end{tabular}

Appendix continued

\begin{tabular}{|c|c|}
\hline Variable & Values \\
\hline $1_{\mathrm{a}}$ & 20 \\
\hline$E_{\mathrm{n}}$ & 200 \\
\hline$E_{\text {np }}$ & 300 \\
\hline$r_{\mathrm{c}}$ & 200 \\
\hline DP & vis $* \log \left(r_{\mathrm{c}} / r_{\mathrm{w}}\right) /\left(2 * \mathrm{pi}^{*} K_{\mathrm{or}} * K_{\mathrm{Q}}\right)$ \\
\hline$d$ & 443.484 \\
\hline$v_{\mathrm{r}}$ & $\left(\mathrm{DP} * K_{\mathrm{abs}} * \mathrm{~K}_{\mathrm{or}} * K_{\mathrm{Q}}\right) /\left(v_{\mathrm{is}} * \log \left(r_{\mathrm{c}} / r_{\mathrm{w}}\right) * r_{\mathrm{e}} * d\right)$ \\
\hline$P_{\mathrm{o}}$ & 0.22 \\
\hline $\tan$ & $\tan (\mathrm{Po})$ \\
\hline$n$ & $3 / \mathrm{Po}^{*}(1 / \tan -1 / \mathrm{Po})$ \\
\hline$A$ & $\mathrm{pi}^{*} \mathrm{~d}^{\wedge} 2 / 4$ \\
\hline$u$ & $\mathrm{Q} / \mathrm{A}$ \\
\hline$D$ & 0.2 \\
\hline$f_{\mathrm{g}}$ & 0.023 \\
\hline$r_{\mathrm{d}}$ & $\mathrm{d} / 2$ \\
\hline$v$ & $\mathrm{Q} /\left(2 * \mathrm{pi}^{*} r_{\mathrm{d}} * 200\right)$ \\
\hline$B$ & 50 \\
\hline alpha & 0.1 \\
\hline$R_{\mathrm{c}}$ & 200 \\
\hline$T_{\mathrm{r}}$ & $\left(2 *\right.$ alpha $\left.* r_{\mathrm{w}}\right) /\left(\mathrm{la} * \mathrm{C} 0 * \mathrm{Rc}^{\wedge} 2\right)$ \\
\hline$X_{\mathrm{w}}$ & $\left(r_{\mathrm{w}} / R_{\mathrm{c}}\right)^{\wedge} 2$ \\
\hline RAmi & $n^{*}((1-\mathrm{Po}) / \mathrm{Po}) * \mathrm{rho}^{*} q_{\mathrm{t}}$ \\
\hline$r_{2}$ & $(1-\mathrm{Po}) / \mathrm{Po} *\left(3 * f_{\mathrm{g}} / R_{\mathrm{g}}\right)$ \\
\hline$r_{3}$ & $\mathrm{C}-\left(\mathrm{CT} \mathrm{T}^{*} 1^{*} \mathrm{C}\right) /(1+\mathrm{k} 1 * \mathrm{C})$ \\
\hline RAma & $r 2 * r 3$ \\
\hline$R_{\mathrm{d}}$ & RAmi + RAma \\
\hline$K_{\mathrm{c}}$ & $1 /\left(1+B^{*} C\right)$ \\
\hline$K_{\mathrm{c} 1}$ & $1 / K_{\mathrm{c}}$ \\
\hline$r_{\mathrm{c}} r_{\mathrm{w}}$ & $1 /\left(\log \left(r_{\mathrm{e}} / r_{\mathrm{w}}\right)\right)$ \\
\hline$J$ & $1+K \mathrm{c} 1 * r_{\mathrm{c}} r_{\mathrm{w}}$ \\
\hline $\mathrm{DP}_{3}$ & $\left(\mathrm{Q}^{*} \mathrm{vis}\right) /\left(2 * \mathrm{pi}^{*} K_{\mathrm{or}}\right) *\left(\log \left(r_{\mathrm{e}} / r_{\mathrm{w}}\right)+K_{\mathrm{c} 1}\right)$ \\
\hline$I J$ & $1 / \mathrm{J}$ \\
\hline $\mathrm{vr}_{1}$ & $\left(\mathrm{DP} 3 * K_{\mathrm{abs}} * K_{\mathrm{or}} * K_{\mathrm{Q}}\right) /\left(\operatorname{vis} * \log \left(r_{\mathrm{e}} / r_{\mathrm{w}}\right) * r_{\mathrm{e}} * d\right)$ \\
\hline$Q_{\mathrm{n}}$ & $1 \mathrm{a} * \mathrm{vr} 1 * C$ \\
\hline$R$ & $-\left(Q_{\mathrm{n}}+R_{\mathrm{d}}\right)$ \\
\hline
\end{tabular}

\section{References}

Abou-Sayed AS, Zaki KS, Wang GG, Sarfare MD (2005) A mechanistic model for formation damage and fracture propagation during water injection. In: Paper 94606 presented at the SPE European formation damage conference, Sheveningen

Abou-Sayed AS, Zaki KS, Wang GG, Sarfare MD, Harris MH (2007) produced water management strategy and water injection best practices: design, performance and monitoring. SPEPO 22(1):59-68

Ajay S, Sharman MM (2007) A model for water injection into fracpacked wells. In: Paper SPE 110084 presented at the 2007 annual technical conference, Anaheim CA 
Al-Abduwani FAH (2005) Internal filtration and external filter cake build-up in sandstones. PhD Dissertation, Delft University of Technology, Delft. ISBN 90-9020245-5

Al-Abduwani FAH, van den Broek WMGT, Currie PK (2001) Visual observation of produced water re-injection under laboratory conditions. In: Paper 68977 presented at the SPE European formation damage conference, The Hague

Altoef JE, Bedrikovetsky P, Gomes ACA, Siqueira AG, Desouza AI (2004) Effects of oil water mobility on injectivity impairment due to suspended solids. In: SPE Asia Pacific oil and gas conference

Barkman JH, Davidson DH (1972) Measuring water quality and predicting well impairment. J Petrol Technol 24:865-873

Bedrikovetsky P, Marchesin D, Shecaira F, Souza AL, Milanez PV, Resende E (2001) Characterization of deep bed filtration system from laboratory pressure drop measurements. J Petrol Sci Eng 32:167-177

Bedrikovetsky P, Furtado CA, de Souza ALS, Siquera FD (2007) Internal erosion in rocks during produced and sea water injection. In: SPE paper 107513 presented at the SPE Europec/ EAGE annual conference and exhibition held in London, UK

Chang CK (1985) Water quality considerations in Malaysia's first water flood. In: JPT, September, pp 1689-1698

Clifford PJ, Mellor DW, Jones TJ (1991) Water quality requirements for fractured injection wells. In: SPE 21439, presented at the SPE middle east oil show, November, pp 851-862

Davidson DH (1979) Invasion and impairment of formation by particulates. In: Paper 8210, presented at the SPE annual technical conference and exhibition, Las Vegas

De Zwart AH (2007) Investigation of clogging processes in unconsolidated aquifers near water supply wells. PhD Dissertation, Delft University of Technology, Delft

Dong CY, Wu L, Wang AP (2010) Experimental simulation of gravel-packing in horizontal and highly deviated well. J China Univ Petrol 34(2):74-82

Donaldson EC et al (1977) Particle transport in sandstones. In: Paper SPE 6905, presented at the 1977 SPE, annual technical conference and exhibition, Denver, Colorado

Doresa R, Hussaina A, Katebaha M, Adhama S (2012) Advanced water treatment technologies for produced water. In: Proceedings of the 3rd international gas processing symposium

Farajzadeh R (2002) Produced water re-injection (PWRI)-An experimental investigation into internal filtration and external cake buildup. MSc. Thesis, Delft University of Technology, Delft

Faruk C (2010) Non-isothermal permeability impairment by fines migration and deposition in porous media including dispersive transport. Transp Porous Media 85:233-258

Folarin F, An D, Caffrey S, Soh J, Sensen CW, Voordouw J, Jack T, Voordouw G (2013) Contribution of make-up water to the microbial community in an oilfield from which oil is produced by produced water re-injection. Int Biodeterior Biodegradation 81:44-50

Furtado CJA, Siquera AG, Souza ALS, Correa ACF, Mendes RA (2005) Produced water reinjection in petrobas fields: challenges and perspectives. In: Paper 94705 presented at the SPE Latin American and caribbean petroleum engineering conference, Rio de Janeiro, Brazil

Gong B, Liang H, Xin Z, Li K (2013) Numerical studies on power generation from co-produced geothermal resources in oil fields and change in reservoir temperature. Renew Energy 50:722-731

Greenhill K (2002) Brazil frade fluid properties technical service report. In: EPTC TS02000099, November 15

Guedes RG, Al-Abdouwani FA, Bedrikovetsky, Currie PK (2006) Injectivity decline under multiple particle capture mechanisms. In: Paper 98623 presented at SPE internal symposium and exhibition on formation damage control, Lafayette
Hustedt B, Zwarts D, Bjoerndal HP, Mastry R, van den Hoek PJ (2006) Induced fracturing in reservoir simulation: application of a new coupled simulator to water flooding field examples. In: Paper 102467 presented at spe annual technical conference and exhibition held in San Antonio, Texas, USA

Idialu PO (2014) Modeling of adsorption kinetics, hydrodynamic dispersion and geochemical reaction of produced water reinjection (PWRI) in hydrocarbon aquifer. PhD Thesis, Department of System Engineering, University of Lagos

Iwaski T (1937) Some notes on sand filtration. J Am Water Works Assoc 29:1591

Khatib Z (2007) Produced water management: is it a future legacy or a business opportunity for field development. In: International petroleum technology conference (IPTC 11624), held in Dubai, UAE

Khodaverdian M, Sorop T, Postif S, van den Hoek PJ (2009) Polymer flooding in unconsolidated sand formations: fracturing and geochemical considerations. In: Paper 121840 presented at the SPE Europe/EAGE annual conference and exhibition held in Amsterdam

Lawal AK, Vesovic V (2010) Modeling Asphaltene-induced formation damage in closed systems. In: SPE Paper 138497 presented in international petroleum exhibition and conference, Abu Dhabi

Lawal KA, Vesovic V, Edo SB (2011) Modeling permeability impairment in porous media due to asphaltene deposition under dynamic conditions. Energy Fuels 25:5647-5659

Li M, Li Y, Wang L (2011) Productivity prediction for gravel-packed horizontal well considering variable mass flow in wellbore. J China Univ Petrol 35(3):89-92

Li Y, Li M, Qin G, Wu J, Wang W (2012) Numerical simulation study on gravel-packing layer damage by integration of innovative experimental observations. In: Paper 157927 presented in SPE Heavy Oil Conference held in Calgary, Alberta

Mendez ZDC (1999) Flow of dilute oil-in water emulsions in porous media, $\mathrm{PhD}$, the University of Texas

Nabzar L, Chaveteau G, Roque C (1997) A new model for formation damage by particle retention. In: Paper 31119 presented at the SPE International symposium on formation damage control, lafayette, USA, pp 14-15

Ochi J, Detienne J-L, Rivet P (2007) Internal formation damage properties and oil deposition profile. Soc Petrol Eng. doi:10. 2118/108010-MS

Ojukwu KI, van den Hoek PJ (2004) A new way to diagnose injectivity decline during fractured water injection by modifying conventional hall analysis. In: Paper 89376 presented at the SPE/ DOE 14th symposium on improved oil recovery held in Tulsa, Oklahoma, USA

Pang S, Sharma MM (1994) A model for predicting injectivity decline in water injection wells. In: Paper SPE 28489 presented at the 1994 annual technical conference, New Orleans

Pang S, Sharma MM (1997) A model for predicting injectivity decline in water injection wells. SPE Form Eval 12(3):194-201

Prasad KS, Bryant SL, Sharma MM (1999) Role of fracture face and formation plugging in injection well fracturing and injectivity decline. In: Paper 52731 presented at the 1999 SPE/EPA conference held in Austin, Texas

Sahni A, Kovacevich ST (2007) Produced water management alternatives for offshore environmental stewardship. In: Paper 108893 presented at the SPE Asia Pacific health, safety, security and environment conference and exhibition held in Bangkok, Thailand

Salehi MR, Settari A (2008) Velocity-based formation damage characterization method for produced water re-injection: application on masila block core flood tests. University of Calgary, Alberta

Sharma MM, Pang S, Wennberg KE, Morgenthaler LN (2000) Injectivity decline in water-injection wells: an offshore Gulf of 
Mexico case study. In: SPE production and facilities, February, pp 6-13

Shuler PJ, Subcaskey WJ (1997) Literature review: oily produced water reinjection. CPTC TM97000078 in March

Souza ALS, Figueiredo MW, Kuchpil C, Bezerra MC, Siquera AG, Furtado C (2005) Water management in petrobras: developments and challenges. In: Paper OTC 17258 presented at the offshore technology conference, Houston, Texas, USA

Todd A (1979) Review of permeability damage studies and related North Sea water injection. In: Presented at the society of petroleum engineers international symposium on oilfield and geothermal chemistry, Dallas

Van den Hoek PJ, Matsuura T., Dekroon M, Gheissary G (1996) Simulation of produced water re-injection under fracturing conditions. In: Paper 36846 presented at the SPE European petroleum conference held in Milan, Italy

Wang YF, Le TT (2008) Experimental study on the relationship between sand particle migration and permeability in unconsolidated sandstone reservoirs. J Oil Gas Tech 30(3):111-114

Wang LY, Gaa CX, Mbadinga SM, Zhou L, Liu JF, Gu JD, Mua BZ (2011) Characterization of an alkane-degrading methanogenic enrichment culture from production water of an oil reservoir after 274 days of incubation. Int Biodeterior Biodegradation 65:444-450

Wennberg KE, Sharma MM (1997) Determination of filtration coefficient and transition time for water injection wells. In: Paper 38181 presented at SPE European formation damage conference, The Hague

Yerramilli RC, Zitha PLJ, Yerramilli SS, P (2013) A novel water injectivity model and experimental validation using CT scanned core-floods. In: Paper 165194, presented at the SPE European formation damage conference and exhibition held in Noorwijk

Zeinijahromi A, Lemon P, Bedrikovetsky P (2011) Effects of induced fines migration on water cut during water flooding. J Petrol Sci Eng 78:609-617

Zhang NS, Somerville JM, Todd AC (1993) An experimental investigation of the formation damage caused by produced oily water injection. In: Paper 26702 presented at the offshore Europe, Aberdeen 